BC-TOP-3-A

REVISION 3

AUGUST 1974

\title{
TORNADO AND EXTREME WIND DESIGN CRITERIA FOR NUCLEAR POWER PLANTS
}




\section{DISCLAIMER}

This report was prepared as an account of work sponsored by an agency of the United States Government. Neither the United States Government nor any agency Thereof, nor any of their employees, makes any warranty, express or implied, or assumes any legal liability or responsibility for the accuracy, completeness, or usefulness of any information, apparatus, product, or process disclosed, or represents that its use would not infringe privately owned rights. Reference herein to any specific commercial product, process, or service by trade name, trademark, manufacturer, or otherwise does not necessarily constitute or imply its endorsement, recommendation, or favoring by the United States Government or any agency thereof. The views and opinions of authors expressed herein do not necessarily state or reflect those of the United States Government or any agency thereof. 


\section{DISCLAIMER}

Portions of this document may be illegible in electronic image products. Images are produced from the best available original document. 
CAVEAT: THIS REPORT HAS BEEN PREPARED BY AND FOR THE USE OF BECHTEL POWER CORPORATION AND ITS RELATED ENTITIES. ITS USE BY OTHERS IS PERMITTED ONLY ON THE UNDERSTANDING THAT THERE ARE NO REPRESENTATIONS OR WARRANTIES, EXPRESSED OR IMPLIED, AS TO THE VALIDITY OF THE INFORMATION OR CONCLUSIONS CONTAINED HEREIN. 


\title{
TOPICAL REPORT \\ BC-TOP - 3-A \\ REVISION 3
}

\author{
TORNADO AND EXTREME WIND / \\ DESIGN CRITERIA FOR \\ NUCLEAR POWER PLANTS
}
Prepared by:
J. V. Rotz
G. C. K. Yeh
W. Bertwell

Approved by :

H. W. Wahl

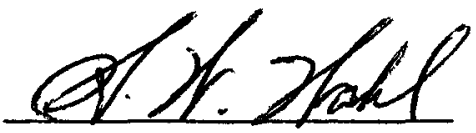

Chief Civil Engineer

Thermal Power Organization 
Mr. John V. Morowski

Vice President-Engineering

Bechtel Power Corporation

Fifty Beale Street

San Francisco, California 94119

Dear Mr. Morowski:

The Regulatory staff has completed its review of Bechtel Power Corporation's Topical Report, BC-TOP-3, Revision 3, dated August 1974 and entitled "Tornado and Extreme Wind Design Criteria for Nuclear Power Plants". 'We conclude that the design criteria and procedures described by this report are acceptable to the Regulatory staff and that BC-TOP-3, Revision 3, is acceptable by reference in applications for construction permits and operating licenses. A summary of our evaluation is enclosed.

BC-TOP-3 does not provide a11 of the pertinent tornado and extreme wind information required by the Regulatory staff in its review of specific applications. Therefore, the supplementary information identified in the Regulatory Position of the enclosed Topical Report Evaluation will have to be provided in individual Safety Analysis Reports.

The staff does not intend to repeat its review of BC-TOP-3, Revision 3 , when it appears as a reference in a particular license application. Should Regulatory criteria or regulations change, such that our conclusions concerning $\mathrm{BC}-\mathrm{TOP}-3$, Revision 3, are invalidated, you will be notified and given the opportunity to revise and resubmit your topical report for review, should you so desire. 
We request that you reissue BC-TOP-3, Revision 3, dated August 1974 in accordance with the provisions of the "Elements of the Regulatory Staff Topical Report Review Program" which was forwarded to you on August 26, 1974. If you have any questions in this regard, please let us know.

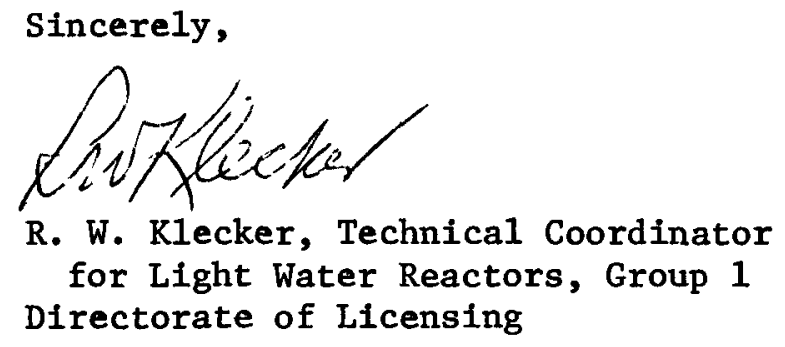

Enclosure:

Toplcal Report Evaluation 
TOPICAL REPORT EVALUATION

Report No.: BC-TOP-3 Rev. 3

Report Title: Tornado and Extreme Wind Design Criteria for Nuclear Power Plants

Report Date: August 1974

Originating Organization: Bechtel Power Corporation

Reviewed by: Structural Engineering Branch, Site Analysis Branch and Auxiliary Power and Conversion System Branch, all of Directorate of Licensing, September 1974

\section{SUMMARY OF REPORT}

This report contains criteria for design of nuclear power plant structures for extreme winds and tornado effects. Extreme wind criteria cover wind velocities up to and including hurricanes. The extreme wind velocities specified herein, are identical to those defined by wind speed map of ANSI Building Code requirements A58. 1-1972. The velocities defined correspond to a mean recurrence interval of 100 years.

Extreme wind loading is applied to structures using methods and procedures consistent with the ANSI Code. The wind load provisions of the ANSI Code, as modified herein, are an essential part of these criteria. Combinations of extreme wind loads with other loads and maximum allowable values of stress and strain are not included in the report. This information will be specified in individual plant SAR.

For the parameters defining tornado size, intensity, loading, depressurization characteristics and others, the report refers to the plant SAR.

Velocity pressures resulting from tornado winds are applied using procedures paralleling those for extreme winds, the primary differences being the treatment of the tornado horizontal and vertical pressure profiles as opposed to those considered in extreme wind design. To facilitate use of the material contained in the ANSI Code, parallel definitions of velocity pressures for determining overall loading, local loading and internal pressures have been developed. 
In addition to velocity pressure loading, methods and procedures for determining the magnitude and combined effects of a tmospheric pressure change and tornado missile impact are included.

For the load combinations involving tornado effects, and associated design allowables the report refers to individual plant SAR. For structures with no openings, differential pressures due to full and partial effects of atmospheric pressure change are considered in design. For structures with openings (vented) the differential pressure loading is calculated using Bechtel computer program CE 899. Differential pressures on exterior walls calculated by the code (one dimensional analysis) are to be multiplied by a 1.20 factor of safety to account for possible non-conservatism due to the threedimensional flow effects.

A cross-reference listing of items in this report related to Atomic Energy Commission Safety Analysis Report format is provided in Appendix A. Symbols and notations that are generally consistent with those adopted by the ANSI Code are contained in Appendix B. Development of supporting tornado criteria is included in Appendix $C$. Appendix $D$ describes a one dimensional computer program for calculating building depressurization effects and references are contained in Appendix $E$. SUMMARY OF THE REGULATORY EVALUATION

The Structural Engineering, Site Analysis and Auxiliary Power and Conversion Systems Branches of the Directorate of Licensing have reviewed the subject report, including Appendices $A, B, C$ and $D$. The procedures covered by this report with augmentation of pertinent information that is referred to and to be provided in plant SAR, are judged to represent the present "state of the art" in the field of desian of structures against wind and tornado loadings. If properly utilized in nuclear power plant structural design work, the 
procedures and criteria contained in the report should provide conservative and acceptable bases.for design of nuclear power plant structures.

\section{REGULATORY POSITION}

The design criteria and procedures described by this report are acceptable to the Regulatory Staff. The report may be referenced in future case applications provided that the following specific information reviewed and accepted by the Regulatory Staff is included in individual SAR:

a. Parameters that define tornado loading, such as, translational and maximum tornado wind velocities, rate of depressurization, radius of maximum tornado wind velocity and amplitude of maximum pressure drop, etc.

b. Applicable wind velocities higher than those shown in Fig. 2 of the report as required by unique site conditions.

c. Combinations of extreme wind loads, $W$, with other loads and maximum allowable stress and strain.

d. A list of Category I and non-Category I structures, systems and components to which extreme wind design criteria are applied.

e. A list of all safety-related structures that are to be designed to resist the effects of tornadoes. 
TOPICAL REPORT

BC-TOP-3

TORNADO AND EXTREME WIND

DESIGN CRITERIA FOR

NUCLEAR POWER PLANTS

ABSTRACT

This report contains nuclear power plant design criteria for tornadoes and extreme winds. It includes data, formulation and procedures for determining maximum wind loading on structures and parts of structures.

Extreme wind loading is applied to structures using methods and procedures consistent with the ANSI Building Code requirements A58.1-1972 (Ref. 1). The basic design wind velocities are defined by the wind speed map, Fig. 2-1 (from Ref. 1, Fig. 2) for 100-year mean recurrence interval winds.

Tornado wind loading is applied to structures using procedures paralleling those for extreme winds with additional criteria resulting from the atmospheric pressure change accompanying tornadoes and tornado missile impact effects.

Parameters (velocities, pressure drop and geometry) defining the magnitude of the tornado upon which plant design is based are specified in the plant Safety Analysis Report (SAR).

A cross reference listing of items in this report related to Atomic Energy Commission Safety Analysis Report format is provided in Appendix A. Development supporting tornado criteria is included in Appendix $C$ and Appendix D. 
1.0 INTRODUCTION I-1

2.0 EXTREME WINDS 2-1

2.1 Extreme Wind Phenomena 2-1

2.2 Basic Wind Velocities 2-1

2.3 General Provisions 2-1

2.4 Special Considerations 2-2

2.5 Load Combinations 2-2

3.0 TORNADOES 3-1

3.1 Tornado Phenomena 3-1

3.2 General Provisions 3-2

3.3 Tornado Design Parameters 3-2

3.3.1 Maximum Wind Velocities 3-2

3.3.2 Atmospheric Pressure Change 3-3

3.3.3 Tornado Missiles 3-3

3.4 Load Combinations 3-3

3.5 Load Determination 3-3

3.5.1 Velocity Pressure Loading 3-3

3.5.1.1 Velocity Pressures 3-4

3.5.2 Atmospheric Pressure Change Loading 3-5

3.5.3 Missile Impact Effects 3-6

3.6 Special Considerations 3-6

3.6.1 Differential Pressures On Internal Components 3-6

3.6.2 Protection of Exterior Openings 3-6

3.6.3 Special Shapes $3-6$

3.6.4 Dynamic Excitation $3-7$

3.6.5 Limited Damage 3-7

3.6.5.1 Missile Damage 3-7

3.6.5.2 Loss of Sheathing 3-7

3.6.5.3 Cranes 3-8

3.6.5.4 Other Structures 3-8

3.6.6 Exposed Category I Bodies of Water 3-8

4.0 EXAMPLES AND ILLUSTRATIONS 4-1

4.1 Velocity Pressure Coefficients 4-1

4.2 Extreme Wind Velocity Pressures 4-1

4.3 Tornado Pressure Loading 4-2

4.3.1 Velocity Pressures 4-2

4.3.2 Velocity Pressure Coefficients 4-3

4.3.3 Atmospheric Differential Pressures 4-4

4.4 Frame With Detached Sheathing 4-4

4.5 Structure With Blowout Panel 4-4

4.6 Partially Vented Structure 4-5 
Revision 3

\section{APPENDICES}

Appendix A Cross Reference Listing To AEC Format

Appendix B Notation

Appendix C Supporting Derivations For Tornado Design Criteria

Appendix D Computer Program For Building Depressurization Bechtel Corporation Program CE 899

Appendix E Rèferences 


\section{LIST OF FIGURES}

2-1 Basic Wind Velocity, V30 (mph) - 100-Year Mean

Recurrence Interval (from Ref. 1)

3-1 Idealized Atmospheric Pressure Change Vs. Time Function

3-2 Velocity Pressure Variation with Radius from Center of Tornado

3-3 Size Coefficient, $C_{s}$, for Average Tornado Velocity Pressure Loading

4-1. Local Pressure Coefficients for Rectangular Building with Gabled Roof

4-2 Local Pressures on Rectangular Building with Flat Roof

4-3 Velocity Pressure Distribution - Cylinders and Spheres

4-4 Drag Coefficient Vs. Aspect Ratio - Suspended Rectangular Members

4-5 Extreme Wind Velocity Pressure Distribution on Typical Building

4-6 Tornado Velocity Pressure Loading on steel Frame with Detached Sheathing

4-7 Typical Sheathing Failure Pattern (3-Span Sheathing)

4-8 Pressures on Structure Before Blowout Panel Releases and at Maximum Wind Velocity (psf)

4-9 Illustration of Pressure Distribution and Flow Pattern during Building Depressurization

4-10 Illustration of a Structure Depressurization Model

4-11 Differential Pressure Time History for Compartments 1 and 3

Cl-1 Atmospheric Pressure Change Variations with Radius and Time 
This report contains criteria for design of nuclear power plant structures for extreme winds and torando effects. Extreme wind criteria cover wind velocities up to and including hurricanes. The extreme wind velocities specified herein (defined by wind speed map, Fig. 2-1 from ANSI Building Code requirements A58.1-1972, Fig. 2, Ref. 1) correspond to a mean recurrence interval of 100 years.

Extreme wind loading is applied to structures using methods and procedures consistent with Ref. 1 . The wind load provisions of Ref. 1, as modified herein, are an essential part of these criteria. Although it is assumed in this report that the reader (or user) is thoroughly familiar with the provisions contained in Ref. 1, additional data and explanatory material are included to facilitate application of these provisions.

Parameters defining tornado loading are specified in the plant SAR.

Velocity pressures resulting from tornado winds are applied using procedures paralleling those for extreme winds, the primary differences being the treatment of the tornado horizontal and vertical pressure profiles as opposed to those considered in extreme wind design. To facilitate use of the material contained in Ref. I, parallel definitions of velocity pressures for determining overall loading, local loading and internal pressures have been developed.

In addition to velocity pressure loading, methods and procedures for determining the magnitude and combined effects of atmospheric pressure change and tornado missile impact are included along with special considerations peculiar to nuclear power plant facilities.

A cross-reference listing of items in this report related /3 to Atomic Energy Commission Safety Analysis Report format is provided in Appendix A. Symbols and notation consistent with this report and Ref. 1 are contained in Appendix B. Development supporting tornado criteria is included in Appendix $C$. Appendix D describes a computer program for calculating building depressurization and references are contained in Appendix $\mathrm{E}$. 


\subsection{EXTREME WINDS}

\subsection{Extreme Wind Phenomena}

Extreme winds are defined for the purpose of this document as winds with a vertical gradient, occurring over a wide area, and having velocities up to and including hurricane intensity.

The 100-year mean recurrence interval extreme winds in these design criteria (Fig. 2-1) are based on the data in "Climatological Data, National Summaries" from the U. S. Weather Bureau. If local conditions indicate higher wind velocities than shown in Fig. 2-1, such velocities will be addressed in the SAR. Local conditions, if more severe, shall govern.

\subsection{Basic Wind Velocities}

The basic design wind speeds are shown in Fig. 2-1. Criteria for surburban areas and cities are generally less severe, but are not used in the design of nuclear plants regardless of plant location.

\subsection{General Provisions}

Extreme wind design criteria are applied to Category I and non-Category I structures, systems, and components as defined in Ref. 4 and listed in the plant SAR. These structures are designed for the basic wind velocities shown by Fig. 2-1. Except as otherwise noted herein, the provisions of Ref. 1 for Exposure $C$ (flat, open terrain) shall be followed in applying extreme wind loads.

Other structures are designed in accordance with local or regional governing building codes, if so provided in the project design criteria, or in compli- |3 ance with Ref. 1, whichever is the more severe. 


\subsection{Special Considerations}

The effective velocity pressures given in Table 5 of Ref. I take into account the dynamic response to gusts of ordinary buildings and structures in a direction parallel to the wind and should be considered minimum. Design of structures subject to dynamic excitation, such as vortex shedding from chimneys, shall be based on a detailed dynamic investigation. See Section 6.3.4.1 of Appendix A of Ref. 1, and Ref. 5.)

\subsection{Load Combinations}

Combinations of extreme wind loads, W, with other loads, and maximum allowable values of stress and strain, are specified in the plant Safety Analysis Report (SAR). 


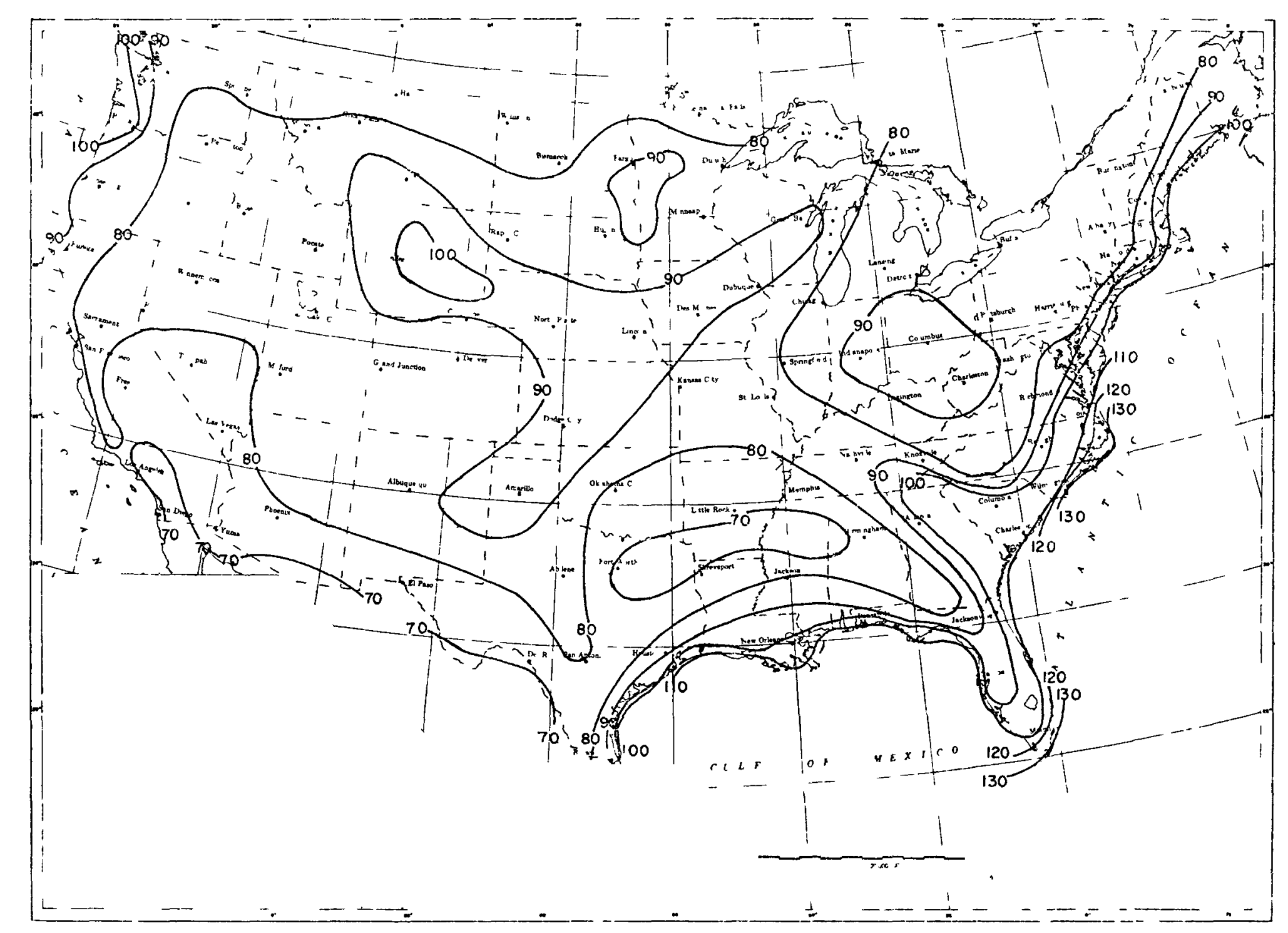

Figure 2-1 Basic Wind Velocity, $\mathrm{V}_{30}(\mathrm{mph})-100$-Year Mean Recurrence Interval (from Ref. 1) 
3. 0 TORNADOES

3.1 Tornado Phenomena

Tornadoes are highly localized wind storms characterized by high velocity winds varying in intensity with the radial distance from the center or axis of the tornado.

For developing structural design criteria, a single vortex tornado is considered. Maximum wind velocity occurs at a distance from the center of the tornado, called the radius of maximum wind, $R_{m}$. Wind velocity increases with distance from the center to the radius of maximum wind, beyond which velocitydecreases, varying inversely with the radius. This results in a horizontal velocity pressure profile peaking at the radius of maximum wind. Wind velocity also varies with height, but to a much lesser degree than the horizontal variation with radius. The vertical velocity pressure profile is assumed to be uniform. Design velocity pressure loading from tornado winds $\left(w_{t g}\right)$ is therefore based on the horizontal pressure profile.

The rotational motion of the air mass about the center of a tornado produces a pronounced change in atmospheric pressure which can, in the case of closed or partially vented structures, produce additional direct differential pressure loading $\left(w_{t_{p}}\right)$ as the tornado passes over a structure. This change is minimal at the outer periphery of the tornado and reaches a maximum at its center.

Tornado-resistant structures must also be designed to resist missile impact effects from airborne objects and debris (from failed or damaged structures and equipment) which are transported by tornado winds. Due to the rotary motion of the tornado winds, missiles tend to be ejected from the tornado and generally reach maximum velocities in the vicinity of or beyond the radius of maximum wind. For design purposes, tornado missile impact effects are therefore considered separately or concurrent with velocity pressure and atmospheric pressure change effects at the radius of maximum wind.

Tornadoes vary in size, configuration, intensity and frequency of occurrence depending on local and regional meteorological and topographical conditions. The largest number and most severe tornadoes occur in the eastern portion of the United States. Smaller and less severe 
tornadoes have occurred infrequently in isolated portions of the western coastal states. Present storm data are insufficient to determine which areas are not susceptible to tornadoes. Therefore, in the absence of a detailed meteorological investigation for a particular plant location, tornadoes are assumed to occur anywhere within the 48 contiguous United States.

Parameters defining the tornado size, intensity, and characteristics are defined in the SAR for each plant.

3. 2 General Provisions

All safety-related structures that are to be designed to resist the effects of tornadoes will be listed in the plant SAR. All safety-related equipment systems and components shall either be designed to sustain tornado effects without loss of function or shall be protected by a tornado-resistant structure. Other structures and plant equipment shall also be designed or protected so that they will not jeopardize the integrity or function of category I structural systems or components or safety-related equipment by virtue of collapse or detachment of component parts.

\subsection{Tornado Design Parameters}

\subsubsection{Maximum Wind Velocities}

Due to rapid developments in tornado technology, parameters defining maximum wind velocities and geometrical features of the design basis tornado model will be specified in the SAR.

\subsubsection{Atmospheric Pressure Change}

The maximum magnitude and rate of atmospheric pressure change are specified in the plant SAR.

For determining the differential pressure loading resulting from atmospheric pressure change, the idealized pressure-time function shown in Fig. 3-1 can be used in lieu of the more representative formulae contained in Appendix $C$. However, use of the formulation in Appendix $\mathrm{C}$ is preferred where computational difficulties are not a factor. 


\subsubsection{Tornado Missiles}

The tornado missiles to be considered in plant design are identified and characterized in the plant SAR.

\subsection{Load Combinations}

The load combinations involving tornado effects, $w_{t}$, and associated design allowables are specified in the plant SAR.

$w_{t}$ is further defined by the following load equations:

$$
\begin{array}{ll}
\mathrm{w}_{\mathrm{t}}=\mathrm{w}_{\mathrm{tq}} & (\mathrm{Eq} \cdot 3-1) \\
\mathrm{w}_{\mathrm{t}}=\mathrm{w}_{\mathrm{tp}} & (\mathrm{Eq} \cdot 3-2) \\
\mathrm{w}_{\mathrm{t}}=\mathrm{w}_{\mathrm{tm}} & (\mathrm{Eq} \cdot 3-3) \\
\mathrm{w}_{\mathrm{t}}=\mathrm{w}_{\mathrm{tq}}+0.5 \mathrm{w}_{\mathrm{tp}} & (\mathrm{Eq} \cdot 3-4) \\
\mathrm{w}_{\mathrm{t}}=\mathrm{w}_{\mathrm{tq}}+\mathrm{w}_{\mathrm{tm}} & (\mathrm{Eq} \cdot 3-5) \\
\mathrm{w}_{\mathrm{t}}=\mathrm{w}_{\mathrm{tq}}+0.5 \mathrm{w}_{\mathrm{tp}}+\mathrm{w}_{\mathrm{tm}} & (\mathrm{Eq} \cdot 3-6) \\
\mathrm{w}_{\mathrm{tq}}=\text { Velocity pressure effects } & \\
\mathrm{w}_{\mathrm{tp}}=\text { Atmospheric pressure change effects }
\end{array}
$$

Calculated differential pressures (using procedures described in Appendix D) on exterior walls shall be multiplied by a factor of 1.2 .

$\mathrm{w}_{\mathrm{tm}}=$ Missile impact effects

For discussion and derivations supporting these load combinations, see Appendix $C$.

\section{5 Load Determination}

\subsubsection{Velocity Pressure Loading}

Velocity pressure loading, $w_{t q}$, is determined using the methods and procedures contained in Ref. 1 with the following exceptions:

1. Velocity and velocity pressure are assumed not to vary with height.

2. Velocity and velocity pressure vary with horizontal distance from the center of the tornado. For definition of horizontal pressure profile, see Fig. 3-2.

3. Velocity pressures $q F, q p$, and $q M$ are determined in accordance with section 3.5 .1 .1 
4. Criteria for determining velocity pressures

for parts and portions (par. 6.3.4.2 of Ref.1)

are not applicable.

5. Gust factor is taken as unity.

3.5.1.1 Velocity Pressures

Velocity pressures are determined by multiplying the velocity pressure, $\mathrm{P}_{\max }$, at the radius of maximum wind, by the size coefficient, $C_{s}$, defined in Fig. 3-3 (for development of Fig. 3-3 see Appendix C).

$$
\begin{aligned}
& \mathrm{q}=\mathrm{C}_{\mathrm{s}} \mathrm{P}_{\max } \\
& q=q_{F}, q_{P} \text { or } q_{M} \\
& \mathrm{q}_{\mathrm{F}}=\begin{array}{l}
\text { Velocity pressure for overall structural } \\
\text { response (psf) }
\end{array} \\
& q_{P}=\underset{\text { (psf) }}{\text { Velocity pressure for parts and portions }} \\
& \mathrm{q}_{\mathrm{M}}=\text { Velocity pressure for calculating inter- } \\
& \text { nal pressures (psf) } \\
& \begin{aligned}
& \mathrm{P}_{\max }= \text { Velocity pressure at the radius of } \\
& \text { maximum wind (psf) }
\end{aligned} \\
& \mathrm{P}_{\max }=0.00256 \mathrm{~V}_{\max }^{2} \quad(\mathrm{Eq} \cdot 3-8) \\
& \mathrm{v}_{\max }=\text { Maximum design wind velocity as de- }
\end{aligned}
$$

For $q_{F}$ and $q_{P}, c_{s}$ is determined as follows:

1. Determine the load distribution length, I, of the structure or structural element. Length $L$ is the plan distance perpendicular to the direction of the wind over which the wind load can be distributed, (such as by beam, truss, or horizontal diaphragm action) or the mean horizontal extent of the tributary area perpendicular to the direction of the wind.

2. Determine the ratio of length, $L$, to radius of maximum wind, $R_{m}$. (The value of $R_{m}$ is specified in the plant SAR.)

3. Enter Fig. 3-3 with $L / R_{m}$ and read value of $\mathrm{C}_{\mathrm{s}}$. 
The internal velocity pressure, $q_{M}$, depends on the location and distribution of openings. When the size and distribution of openings are relatively uniform around the periphery of the structure, $q_{M}$ is determined from Eq. 3-7 using a value of $L$ equal to the plan dimension of the structure perpendicular to the wind and the same procedure as for external velocity pressures. For unequal size and distribution of openings, $\mathrm{q}_{\mathrm{M}}$ is determined from Eq. 3-7 using the following weighted average technique to determine $C_{s}$.

1. Locate structure within the pressure profile for maximum total wind load by determining the values of $r_{1}$ and $r_{2}$ which satisfy Eq. 3-9:

$$
\begin{aligned}
& \frac{r_{1}}{R_{m}}=\frac{R_{m}}{r_{2}} \quad \text { (Eq. 3-9) } \\
& L=r_{2}-r_{1} \text { (see Fig. 3-3) } \\
& L=\begin{array}{l}
\text { Plan dimension of structure perpen- } \\
\text { dicular to wind direction }
\end{array}
\end{aligned}
$$

2. Determine velocity pressure factor $\mathrm{C}_{\mathrm{q}}$ from Fig. 3-2 for each exposed opening.

3. Determine $C_{s}$ from Eq. 3-10.

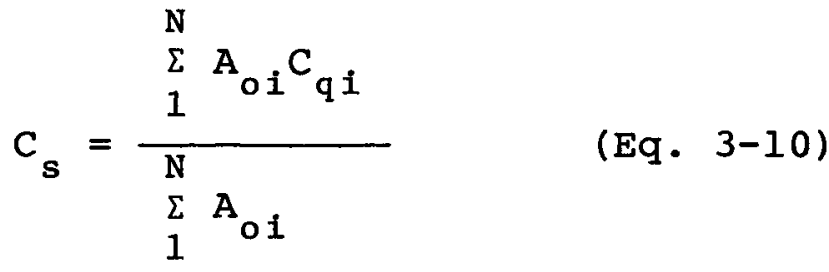

$$
\begin{aligned}
& A_{0 i}=\text { Area of opening at location } i \\
& \mathrm{C}_{\mathrm{q} i}=\underset{\text { Velocity }}{\mathrm{i}} \text { tion pressure factor at loca- } \\
& \mathrm{N}=\text { Number of openings }
\end{aligned}
$$

\subsubsection{Atmospheric Pressure Change Loading}

For structures with no openings (unvented), differential pressures due to atmospheric pressure change are applied in accordance with Eqs. 3-2, 3-4, and 3-6 with the atmospheric differential pressure tending to force external surfaces outward. 
For structures with openings (vented) the differential pressure loading is calculated using a pressure-time function as described in section 3.3.2. Bechtel computer program CE 899 described in Appendix $D$ can be utilized for performing these calculations. Structures with a vent area to compartment volume ratio greater than that of a structure sustaining a maximum differential pressure of 10 psf during the assumed tornado can be considered fully vented.

Differential pressures on exterior walls calculated by procedures contained in Appendix D (CE 899) are multiplied by a factor of 1.2 .

3.5.3 Missile Impact Effects

Missile impact effects are evaluated using the methods and procedures contained in Ref. 3 .

3.6 Special Considerations

3.6.1 Differential Pressures On Internal Components

Internal components (such as tankage, ventilation ducts and equipment, walls, floors, partitions, etc.) must be provided with adequate venting or must be designed for differential pressures resulting from building pressurization and depressurization.

Vents and openings must be located and sized such that exit and entrance velocities will not jeopardize the functional capability of other internal safety-related equipment and components.

3.6.2 Protection of Exterior Openings

Exterior openings and vents in structures required to provide missile protection shall be designed such as to preclude entrance of tornado missiles.

3.6.3 Special Shapes

Lift, drag and/or pressure coefficients for structures or structural elements whose shape and geometry differ appreciably from those of regular buildings and components such as covered in Ref. 1 may be based on well-documented data such as those contained in Ref. 2. For example, Fig. 4-3, based on Table 4 (f) of Ref. 2 can be used to determine wind loads and pressure distribution on containment structures.

Where such data are not available or cannot be developed analytically, special tests are required. 


\subsubsection{Dynamic Excitation}

Design of wind sensitive structures as defined in Ref. 1 and structures subject to dynamic excitation, such as from flutter, gallop and vortex shedding, shall be based on a dynamic investigation such as outlined in Section A6.3.4.1 of Ref. 1 and papers listed in Ref. 1 .

3.6.5 Limited Damage

Structures may sustain limited damage if such damage does not hazard the integrity or functional capability of Category I structures or equipment.

\subsubsection{Missile Damage}

Tornado resistant structures may sustain local missile damage such as partial penetration and local cracking and/or permanent deformation provided that structural integrity is maintained, perforation is precluded and contained Category I equipment is not subjected to damage by secondary missiles, such as from concrete spalling.

\subsubsection{Loss of Sheathing}

Exterior sheathing and nonstructural walls and partitions of structures not required to protect interior systems and components from tornado effects may be considered expendable and allowed to become detached or fail during a tornado, provided such detachment or failure does not constitute a more serious missile hazard than that of the tornado design missiles specified in the SAR.

The structural frame of such structures shall be designed to sustain 1.5 times the pressure at which the sheathing is expected to fail. This loading need not exceed the full pressure loading. These structures shall also be designed for tornado winds acting on the projected area of exposed members and equipment, assuming (for conventional three-span sheathing) onethird of the sheathing remains on the windward portion of the building. Sheathing which is supported by more than four girts or purlins will be treated on a special case basis.*

*Previous analyses and observations have indicated no isignificant difference in wind load on frames where special sheathing has been used. However, this check shall be made to confirm the adequacy of the structure. 
The tributary load from expendable interior nonstructural walls and partitions shall be taken as 1.5 times the pressure loading at which they are expected to fail, but need not exceed full tornado velocity pressure loading.

3.6.5.3 Cranes

Cranes exposed to tornado winds by virtue of loss of expendable sheathing may sustain functional damage but shall be designed to remain on the runway girders so as not to hazard tornado-resistant structures or Category I systems and components.

\subsubsection{Other Structures}

The design or location of other structures not designated as tornado-resistant structures shall be such as not to hazard tornado-resistant structures or protected equipment by virtue of collapse or generation of missiles (more severe than those specified in the SAR) from detached portions or contained equipment.

\subsubsection{Exposed Category I Bodies of Water}

Design of small exposed Category I bodies of water (such as the fuel pool) shall consider a water loss amounting to a change in water level of two feet.

Larger exposed bodies of water (such as spray ponds) shall be designed such that water can be supplied from an alternative source on an as-needed basis or shall be tied in with redundant facilities to maintain functional capability. This interim provision will be followed until further investigation enables a closer evaluation of potential water loss. Water transport by tornadoes is discussed in Refs. 7, 8 and 9. 


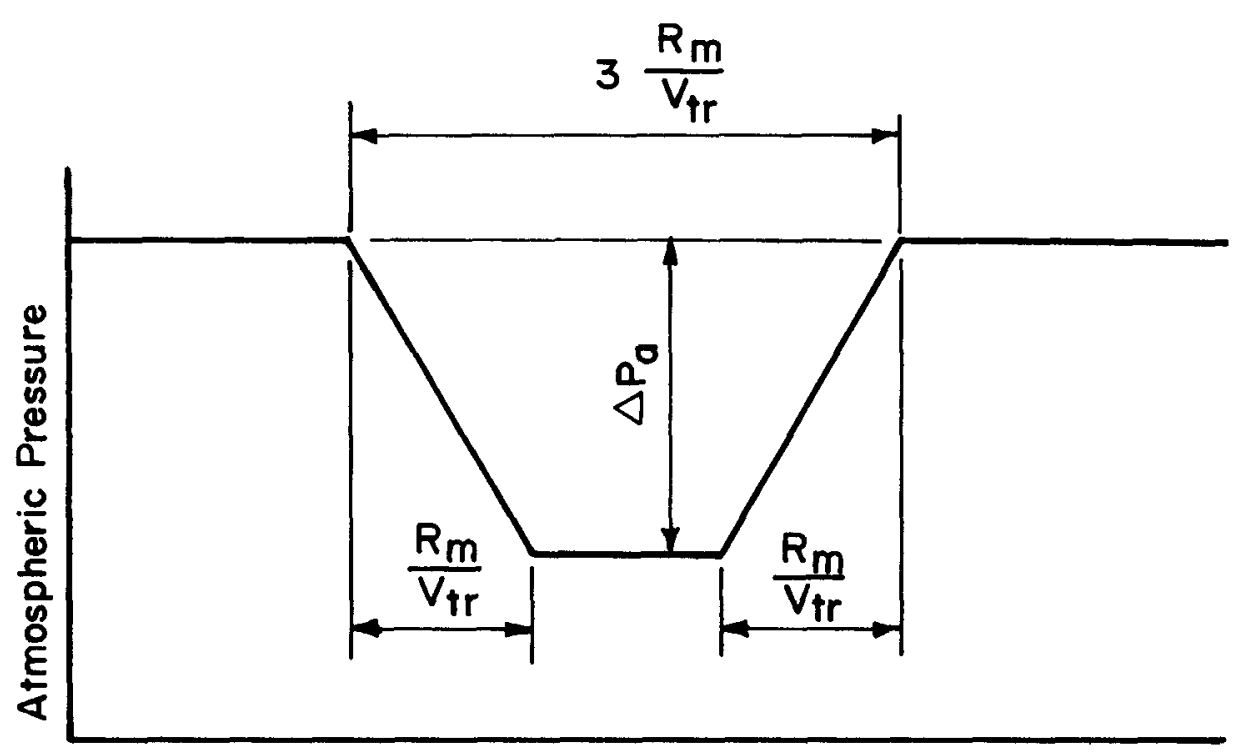

Time

Note: Trapezoidal Approximation of the Theoretical Curve Derived from a Combined Rankine Vortex Velocity Pressure Profile (see Fig. C1-1). For notation see Appendix B.

FIGURE 3-1 Idealized Atmospheric Pressure Change Vs. Time Function 


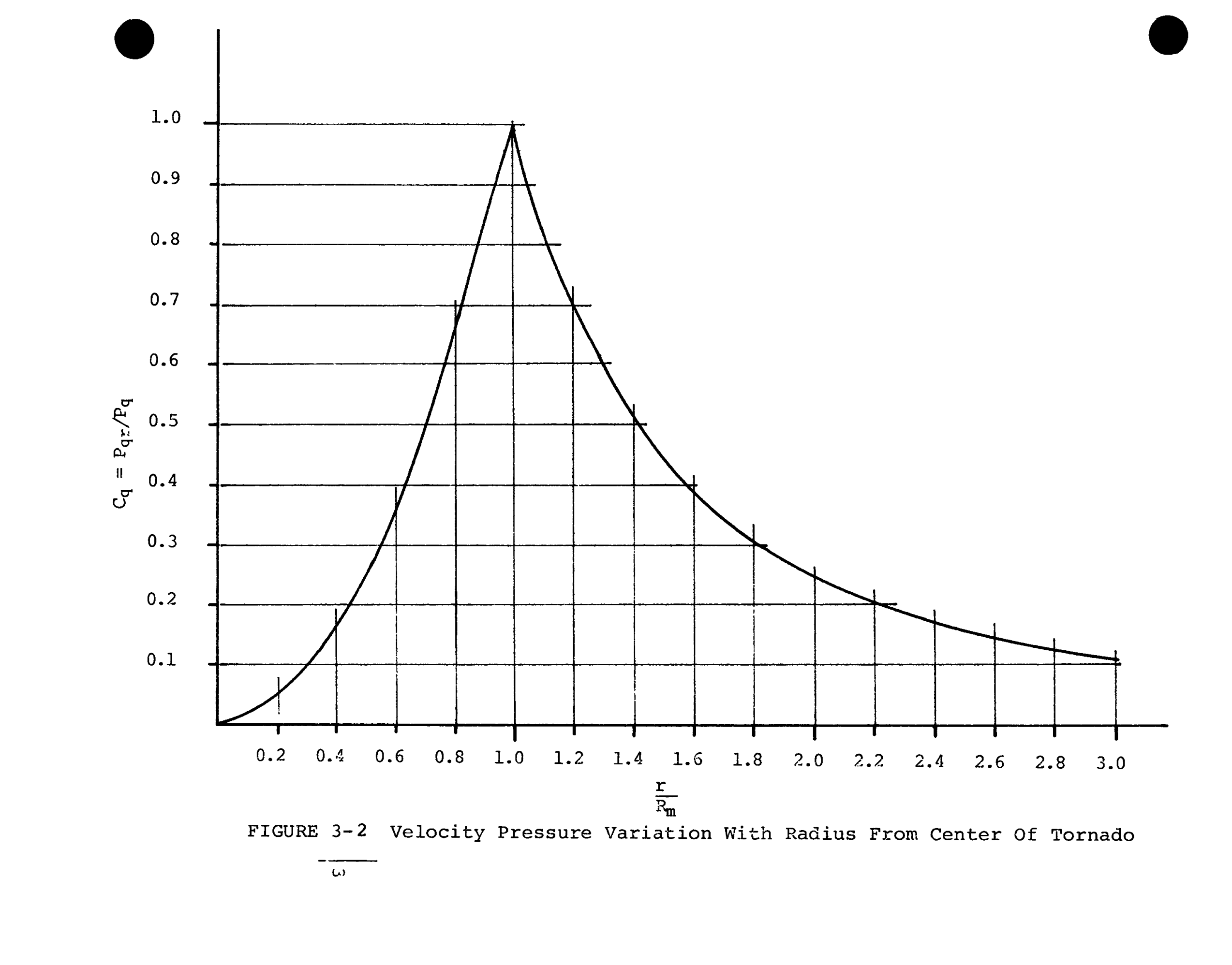




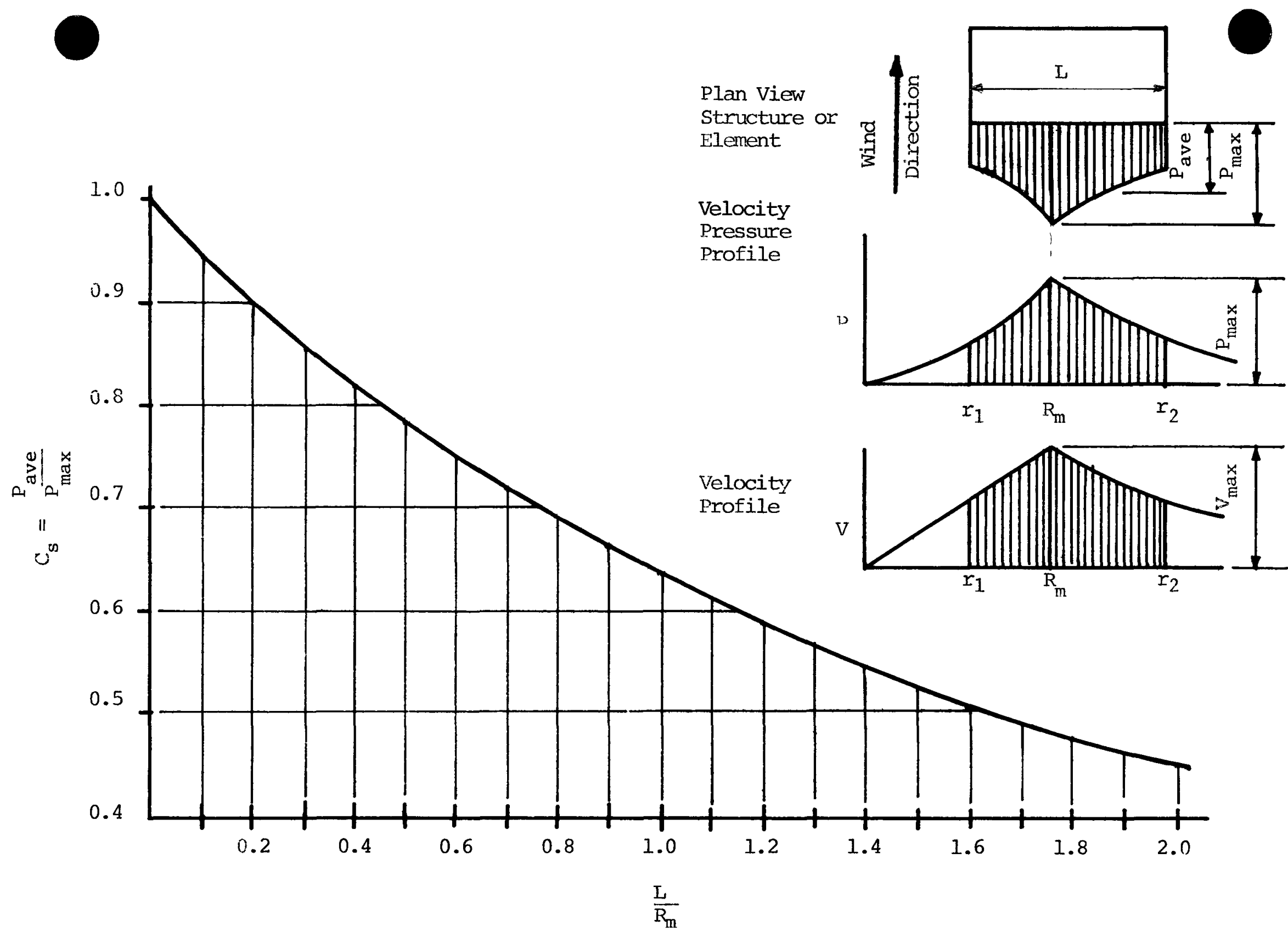

IICUPE 3-3 Size Coefficient, $\mathrm{C}_{\mathbf{s}}$, For Average Tornado Velocity Pressure Loading 
4.0 EXAMPLES AND ILLUSTRATIONS

4.1 Velocity Pressure Coefficients

Velocity pressure coefficients are applicable to both extreme winds and tornado winds. Figs. 4-1 and 4-2 illustrate applications of local external pressure coefficients $\mathrm{C}_{\overline{\mathrm{p}}_{\text {local }}}$ for walls and roofs (Ref. 1).

Local increased loads are applied individually, and not simultaneously with the net external pressures when computing overall loads, nor simultaneously with overlapping local increased loads as at eaves and eave intersections.

An illustration of pressures acting on an overhanging eave is shown in Fig. 4-2. Where the walls extend upward above the roof as parapets, $C_{p}$ for the outer parapet face shall be the same as for the wall, and $\mathrm{C}_{\mathrm{p}_{\text {local }}}$ for the inner face of the parapet shall be -2.4 .

The width of strips subjected to local increased loads need not exceed 12 feet.

Figure 4-3 illustrates the external pressure distribution on cylinders and spheres (Ref. 2) which can be used in the analysis of wind loads on containment structures. Figure 4-4 illustrates the variation of drag coefficient, $C_{D}$, with aspect ratio (ratio of length to width). This figure is applicable to suspended rectangular members (such as structural shapes). If flow around the ends of a member is inhibited such as by other framing members, the length is considered infinite and a drag coefficient of 2 is used.

4.2 Extreme Wind Velocity Pressures

Figure 4-5 illustrates application of extreme wind velocity pressures on a typical building. Pressure coefficients, $\mathrm{c}_{\mathrm{p}}$ and $\mathrm{C}_{\mathrm{pi}}$, correspond to a structure with uniformly aistributed openings and height-towidth and height-to-length ratios less than 2.5 . The variation of velocity pressure with height is also shown schematically. The corresponding variation of internal pressures assumes negligible vertical venting between floors. 


\subsection{Tornado Pressure Loading}

The following example illustrates determination of tornado pressure loading. The steel frame structure shown below is subjected to a tornado with winds from either direction, A or B. For illustrative purposes only, $R_{m}, V_{\max }, V_{t r}$, and $\Delta P_{a}$ have been assumed to be $275 \mathrm{ft} ., 360 \mathrm{mph}, 60 \mathrm{mph}$ and $432 \mathrm{psf}$, respectively.*

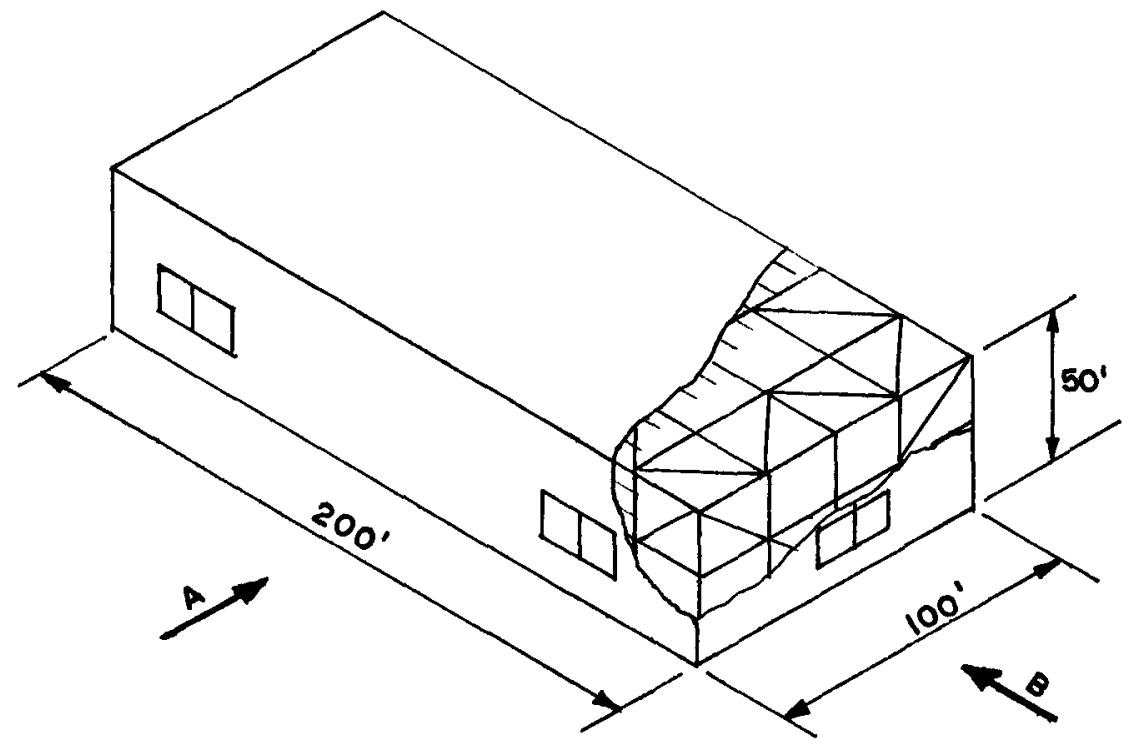

$$
\begin{array}{ll}
\text { AREA OF OPENING } & =1000 \mathrm{FT}^{2} \\
\text { WALL AREA } & =30,000 \mathrm{FT}^{2}
\end{array}
$$

The structure has a horizontal roof truss system, which transmits wind loads to bracing in the side and end walls. Purlins are parallel to the side walls, roof girders span the strucuture in the short direction and bay spacing is 25 feet.

\subsubsection{Velocity Pressures}

The following effective velocity pressures, $q_{F}, q_{P} \quad 13$ and $q_{M}$ for the various structural components and systems were determined using the criteria in section 3.5.1.1 and Fig. 3-3.

*The values of $R_{m}, V_{\max }, V_{t r}$, and $\Delta P_{a}$ to be used in design shall be obtained from the plant SAR. 


\begin{tabular}{|c|c|c|c|c|}
\hline For Internal & $\begin{array}{l}\text { Wind } \\
\text { Direction }\end{array}$ & $\frac{L}{(f t)}$ & $\underline{\mathrm{C}_{\mathrm{s}}}$ & $\begin{array}{l}\text { Effective } \\
\text { Velocity } \\
\frac{\text { Pressure }}{\text { (psf) }}\end{array}$ \\
\hline Pressure & $\begin{array}{l}\mathrm{A} \\
\mathrm{B}\end{array}$ & $\begin{array}{l}200 \\
100\end{array}$ & $\begin{array}{l}.73 \\
.83\end{array}$ & $\begin{array}{l}q_{M}=240 \\
q_{M}=275\end{array}$ \\
\hline For Sheathing & $A \& B$ & 0 & 1.00 & $q_{p}=330$ \\
\hline Roof Truss & $\begin{array}{l}\mathrm{A} \\
\mathrm{B}\end{array}$ & $\begin{array}{l}200 \\
100\end{array}$ & $\begin{array}{l}.73 \\
.83\end{array}$ & $\begin{array}{l}q_{F}=240 \\
q_{F}=275\end{array}$ \\
\hline $\begin{array}{l}100^{\prime} \text { Wal1 } \\
\text { Bracing }\end{array}$ & A & 200 & .73 & $q_{F}=240$ \\
\hline $\begin{array}{l}200^{\prime} \mathrm{Wa} 11 \\
\text { Bracing }\end{array}$ & $\mathrm{B}$ & 100 & .83 & $q_{F}=275$ \\
\hline Roof Girders & $\begin{array}{l}\text { A } \\
\text { B }\end{array}$ & $\begin{array}{r}25 \\
100\end{array}$ & $\begin{array}{l}.96 \\
.83\end{array}$ & $\begin{array}{l}\mathrm{q}_{\mathrm{P}}=315 \\
\mathrm{q}_{\mathrm{P}}=275\end{array}$ \\
\hline Purlins & $\begin{array}{l}\mathrm{A} \\
\mathrm{B}\end{array}$ & $\begin{array}{l}25 \\
0\end{array}$ & $\begin{array}{r}.96 \\
1.00\end{array}$ & $\begin{array}{l}q_{P}=315 \\
q_{P}=330\end{array}$ \\
\hline $\begin{array}{l}200^{\prime} \text { Wall } \\
\text { Cirts \& Columns }\end{array}$ & $\begin{array}{l}\text { A } \\
\text { B }\end{array}$ & $\begin{array}{l}25 \\
0\end{array}$ & $\begin{array}{r}.96 \\
1.00\end{array}$ & $\begin{array}{l}q_{P}=315 \\
q_{P}=330\end{array}$ \\
\hline $\begin{array}{l}100^{\prime} \text { Wall } \\
\text { Girts \& Columns }\end{array}$ & $\begin{array}{l}\mathrm{A} \\
\mathrm{B}\end{array}$ & $\begin{array}{l}0 \\
25\end{array}$ & $\begin{array}{r}1.00 \\
.96\end{array}$ & $\begin{array}{l}q_{P}=330 \\
q_{P}=315\end{array}$ \\
\hline
\end{tabular}

4.3.2 Velocity Pressure Coefficient

Velocity pressure coefficients (based on heightwidth and height-length ratios less than 2.5) are

External Pressure Coefficients, $c_{p}$

Wind Direction

100 ' Wa11s

200' Wa11s

Roof

$\mathrm{A}$
$\mathrm{B}$

A

B summarized as follows:

Columns
Velocity Pre

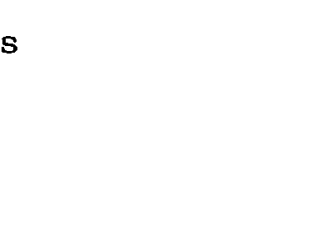

$-.7$

$+.8,-.5$

$+.8,-.5$

$-.7$

A -.7

B

$-.7$
Ref. 1, Table 7

11

11

Ref. 1, Par. 6.5.3.2.1 
Local Pressure Coefficients

\begin{tabular}{|c|c|c|c|}
\hline & $\begin{array}{l}\text { Wind } \\
\text { Direction }\end{array}$ & $\mathrm{C}_{\mathrm{P}_{\text {local }}}$ & \\
\hline Wall Corners & $A \& B$ & -2.0 & Ref. 1, Par. 6.5.3.1 \\
\hline Eaves & $A \& B$ & -2.4 & Ref. 1, Table 10 \\
\hline Roof Corners & $A \& B$ & -5.0 & \\
\hline
\end{tabular}

Internal Pressure Coefficients

$\mathrm{n}=\frac{1,000}{30,000}<0.3$ and evenly distributed

$\mathrm{C}_{\mathrm{pi}}= \pm 0.3$

Ref. 1, Table 11

\subsubsection{Atmospheric Differential Pressures}

Using the idealized pressure-time function shown in Fig. 3-1 and Bechtel computer program CE 899 resulted in a maximum differential pressure of 9 psf. Therefore, the structure can be considered fully vented (Section 3.5.2) and $\mathrm{w}_{\mathrm{tp}}$ can be taken as zero.

4.4 Frame with Detached Sheathing

Figure 4-6 illustrates loading on a frame with sheathing partially removed. One-third of the sheathing on the windward portion of the structure is assumed to remain in place (for three-span sheathing, see Fig. |3 4-7). A drag coefficient of 2 is used for exposed steel members since flow around the ends is restricted by other framing members. The sheathing failure pattern will result in a low aspect ratio for remaining sheathing for which a drag coefficient of 1.2 is appropriate (see Fig. 4-4).

\subsection{Structure With Blowout Panels}

Blowout panels are installed in some structures to prevent (or minimize) differential pressure loading resulting from atmospheric pressure change. Figure 4-8 shows the pressure loading on a $100 \mathrm{ft}$. square structure just prior to blowout panel release and when the structure is subjected to maximum winds $\left(V_{\max }=360 \mathrm{mph}\right)$. The panels are designed to release at a pressure of 100 psf and each has sufficient area to provide full venting. As the tornado approaches the building, negative velocity pressure builds up on the leeward wall. At the same time, differential pressure from atmospheric pressure change 
builds up, tending to force the walls outward. When the sum of these pressures reaches 100 psf, the leeward panel releases. The pressures just prior to panel release are obtained as follows:

1. Determine the value of $r / R_{m}$ for a combined pressure, $\mathrm{P}_{\mathrm{cr}}$, of 100 psf (from Eq. $\mathrm{Cl}-9 \mathrm{~b}$ ) for

$\mathrm{V}_{\mathrm{m}}=290 \mathrm{mph}$ (for $\Delta \mathrm{P}_{\mathrm{a}}=432 \mathrm{psf}$ from Eq. Cl-7a)

$\mathrm{C}=0.5$

$\mathrm{K}=\frac{360}{290}=1.24$

$\frac{r}{R_{\mathbf{m}}}=1.95$

2. Determine corresponding values of $\mathrm{P}_{\mathrm{qr}}$ and $\mathrm{P}_{\mathrm{ar}}$ from Eqs. $\mathrm{Cl}-5 \mathrm{~b}$ and $\mathrm{Cl}-7 \mathrm{~b}$.

$\mathrm{P}_{\text {ar }}=56.4$ psf internal pressure
$\mathrm{P}_{\mathrm{qr}}=43.6$ psf 1 eeward wall
$\mathrm{P}_{\mathrm{qr}}=61.1$ psf roof and side walls
$\mathrm{P}_{\mathrm{qr}}=69.9$ psf windward wall

The pressures before release reflect a value of $C_{s}=1$ (uniform pressure distribution assumed). A value of $\mathrm{C}_{\mathrm{s}}=1$ was also used for internal velocity pressures since the plan dimension of the blowout panel is small. Maximum external pressures correspond to a value of $L$ equal to $100 \mathrm{ft}$.

The other panel is assumed not to release (due to initial inward velocity pressure) unless the direction of the wind reverses and the sum of the internal and external velocity pressures caused a net outward pressure of 100 psf.

\subsection{Partially Vented Structures}

Figure 4-9 illustrates the flow pattern and differential pressure variations in a building undergoing depressurization.

Differential pressure calculation is facilitated by first making a depressurization model for the building such as that shown in Fig. 4-10. Using this model and the pressure-time function shown in Fig. 3-1, the differential pressure-time functions between compartments one and three and between compartment 3 and outside at- 3 mosphere were calculated (using Bechtel computer program CE 899 as described in Appendix D). The resulting pressure-time functions are shown in Fig. 4-11. 


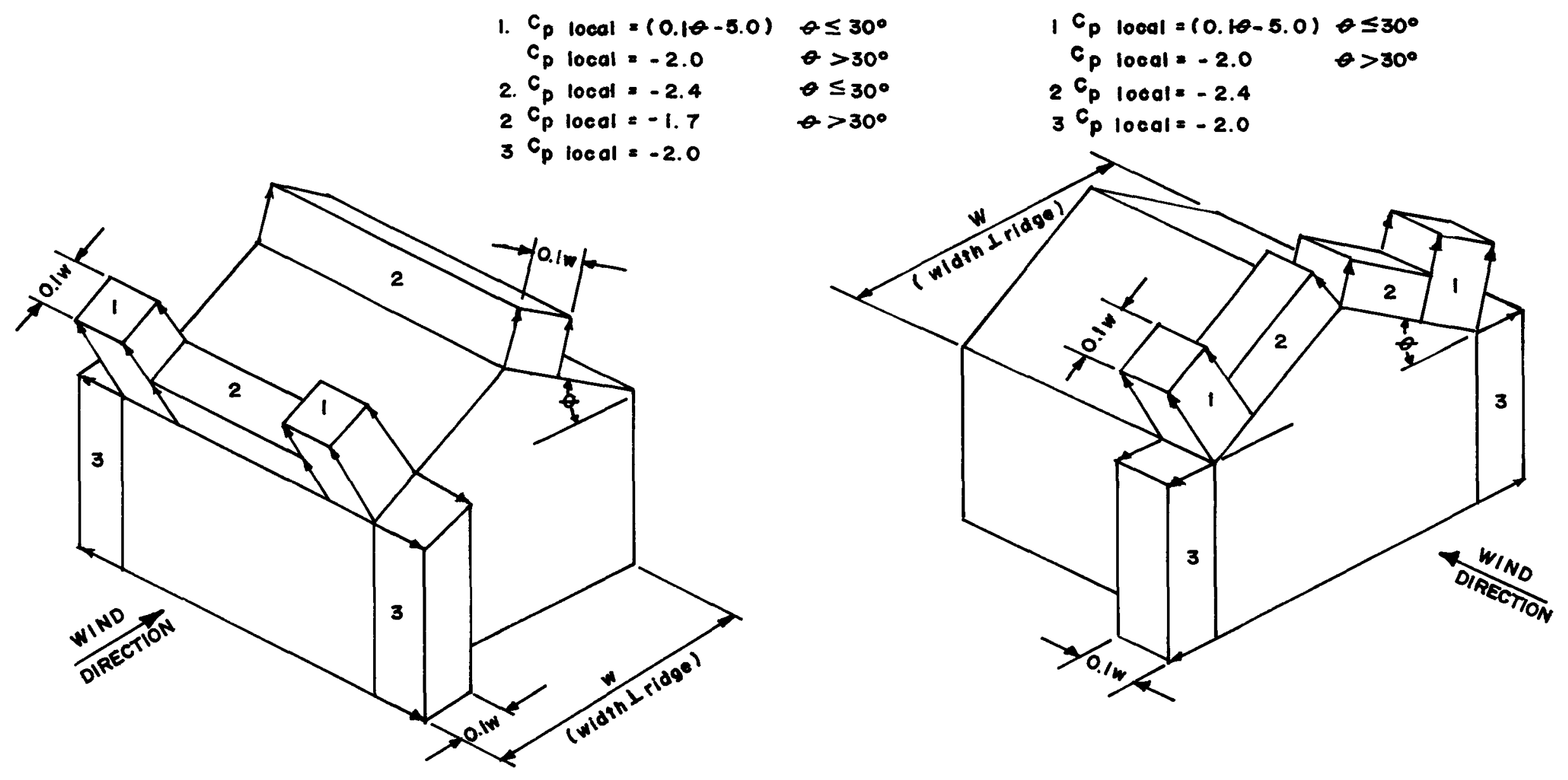

RECTANGULAR BUILDING WITH GABLED ROOF WIND PERPENDICULAR TO RIDGE

RECTANGULAR BUILDING WITH GABLED ROOF WIND PARALLEL TO RIDGE 


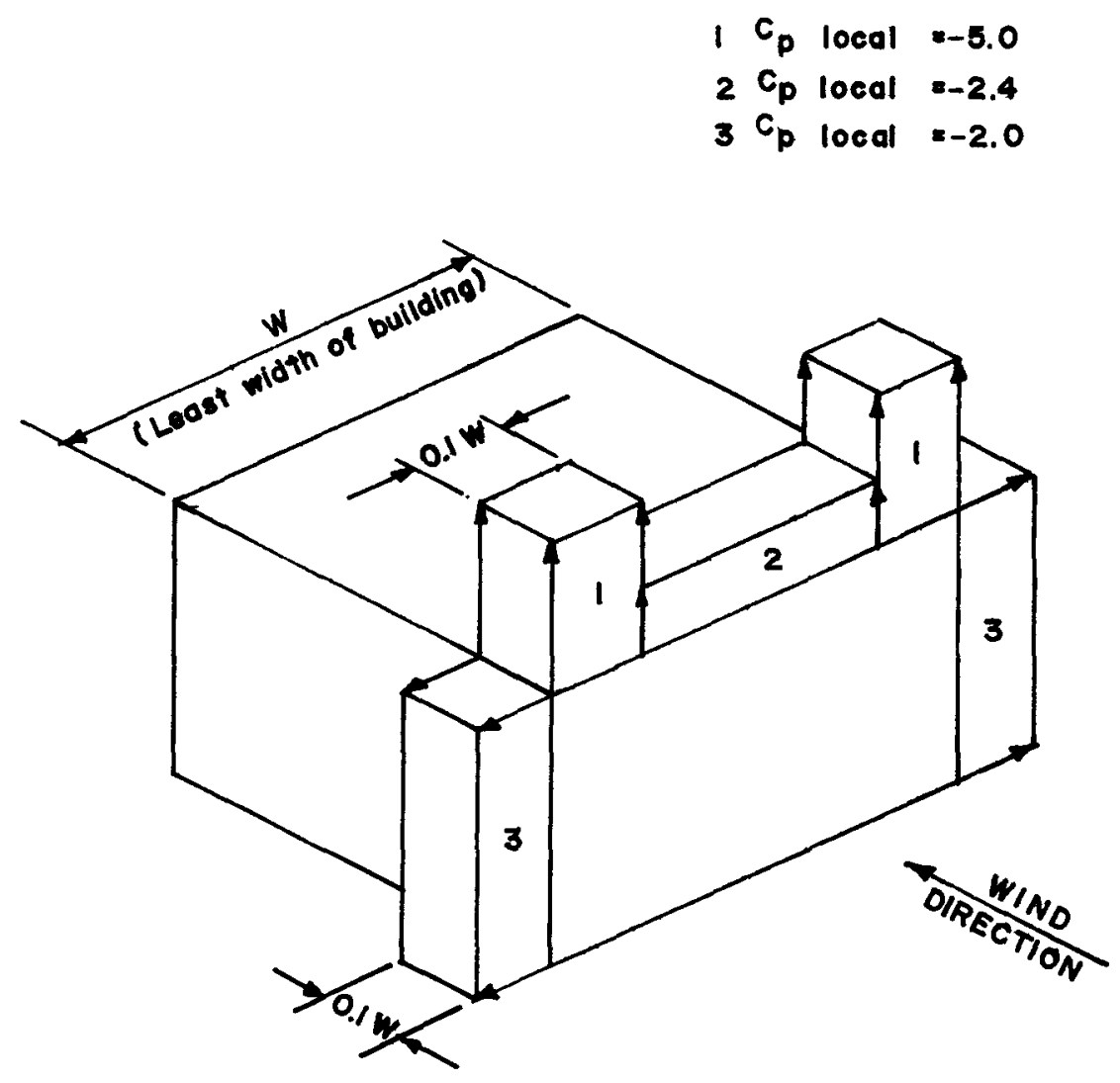

RECTANGULAR BUILDING WITH FLAT ROOF

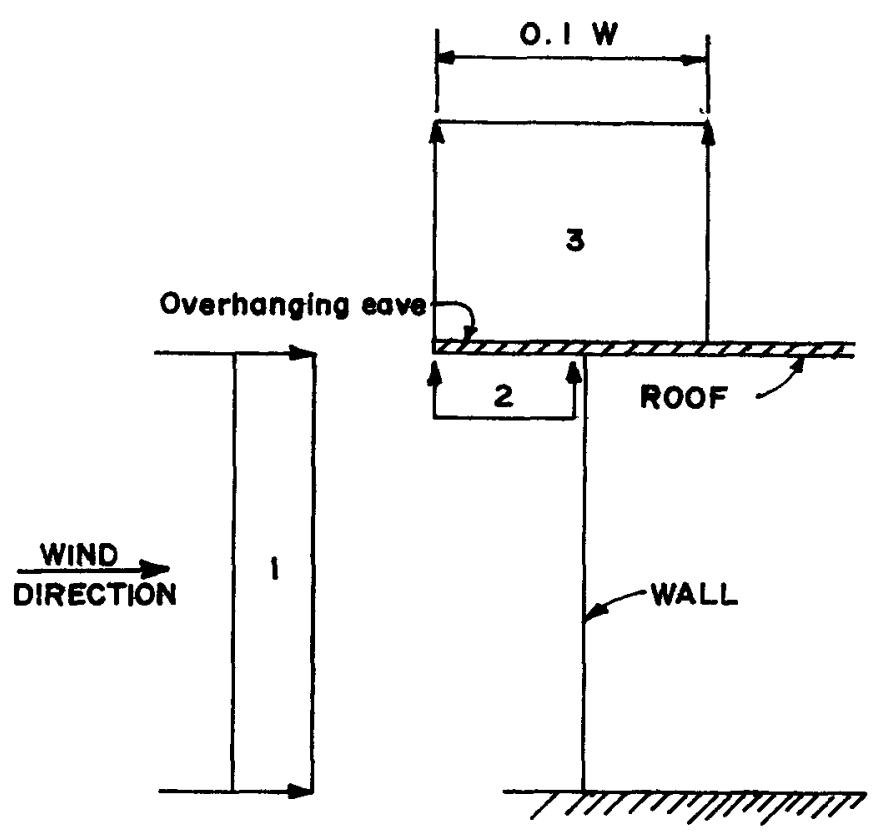

1 pressure $=C_{p} q_{F}$

2 pressure $=C_{p} q_{F}$

3 pressure $=c_{p}$ locol $q_{p}$

COMBINED EXTERNAL PRESSURES ON OVERHANOING EAVE OF BUILDING WITH FLAT ROOF 

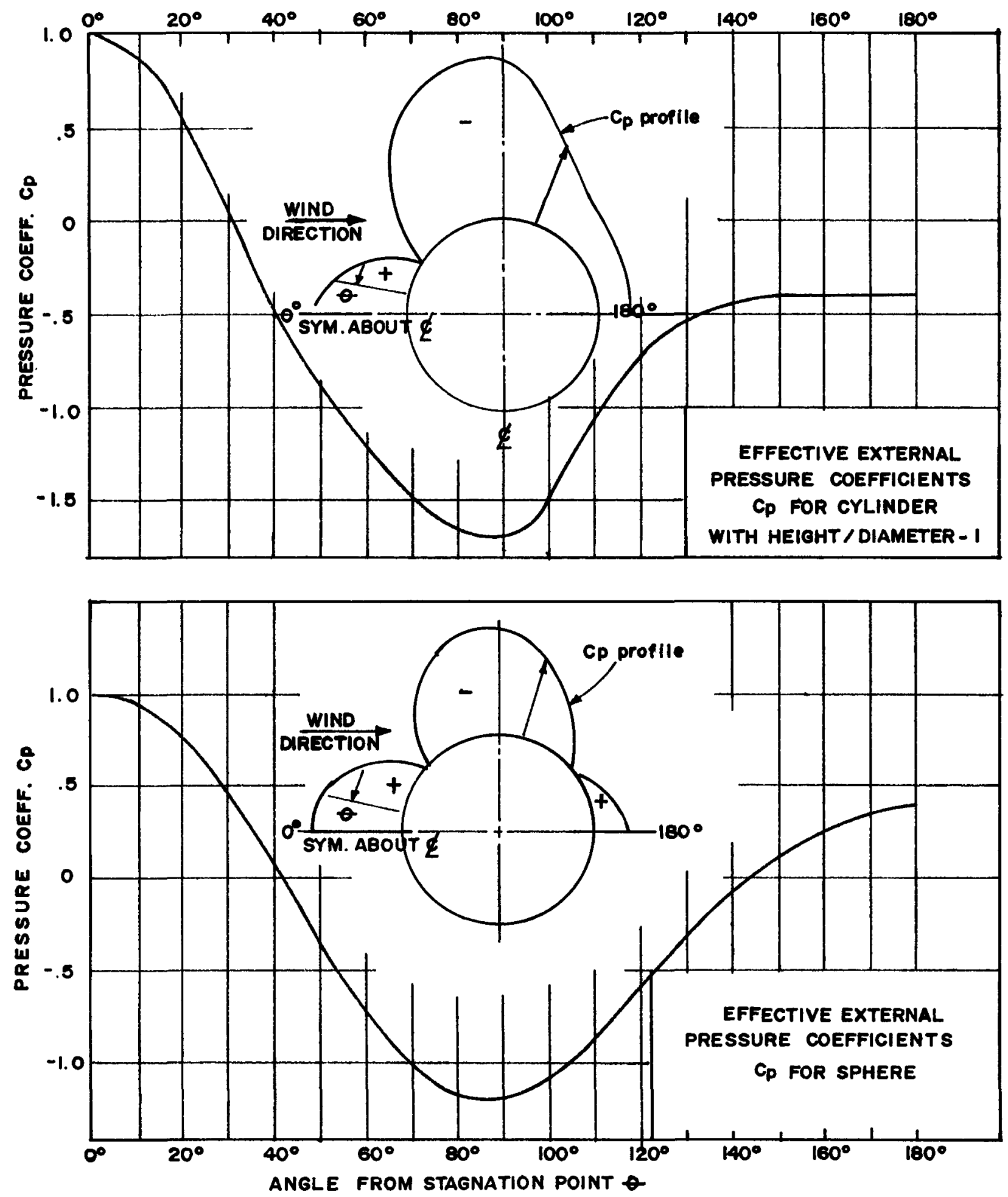

FIGURE 4-3 Velocity Pressure Distribution Cylinders and Spheres 


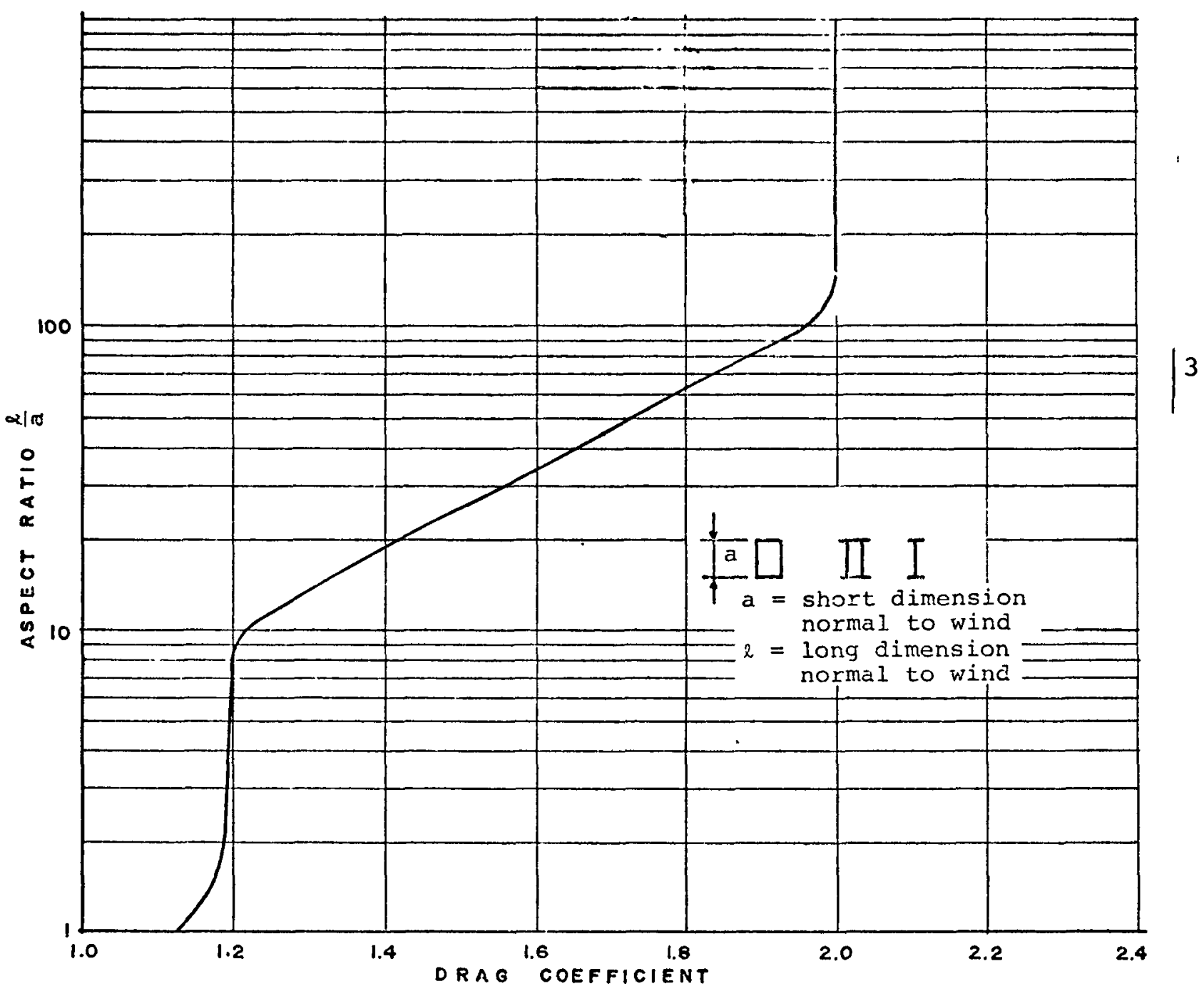

FIGURE 4-4 Drag Cocficient Vs. Aspect Ratio Suspended Rectangular Members 

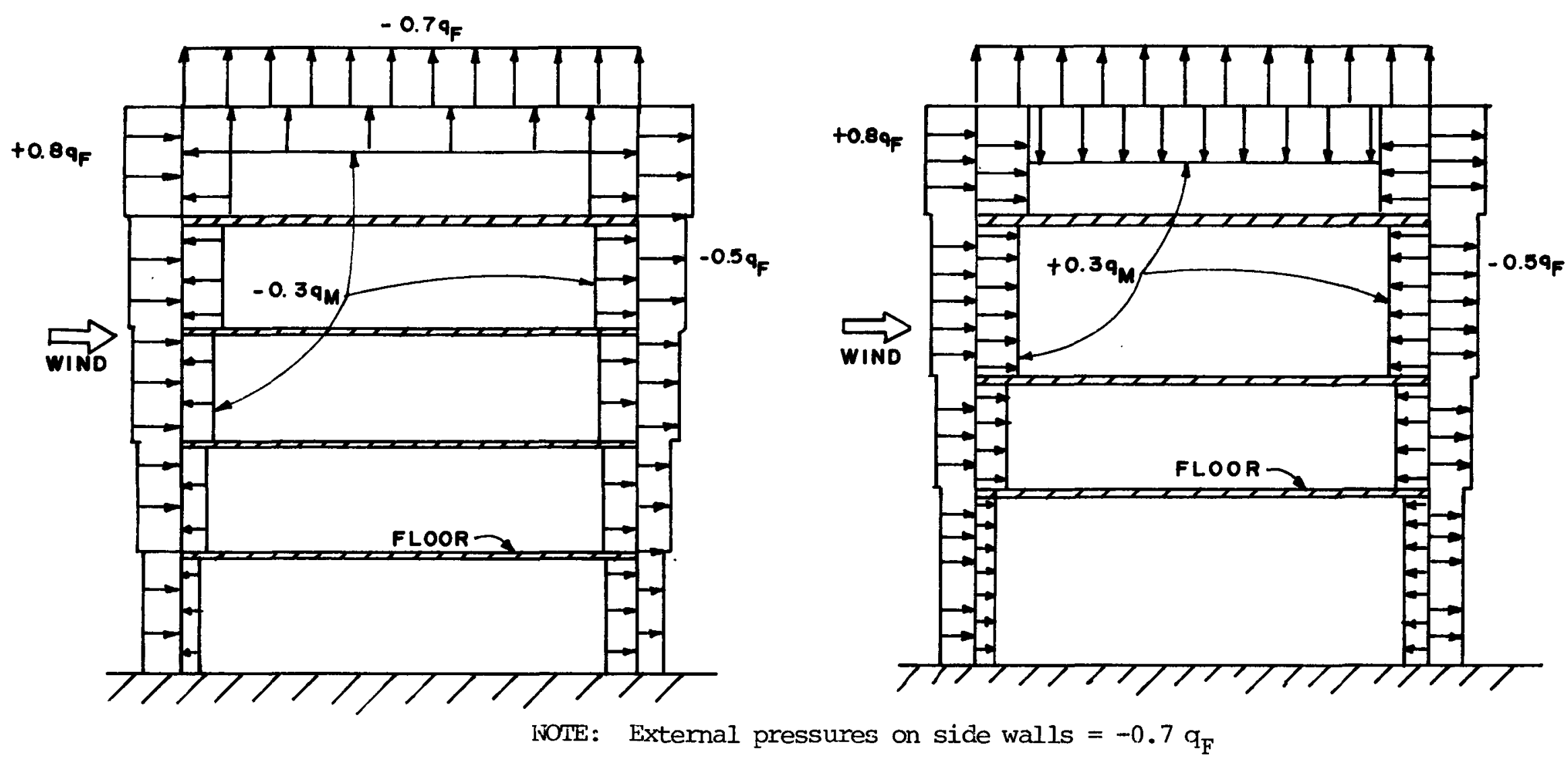

WIND PLUS INTERNAL PRESSURE

WIND PLUS INTERNAL VACUUM

FIGURE 4--5 Extreme Wind Velocity Pressure Distribution on Typical Building 


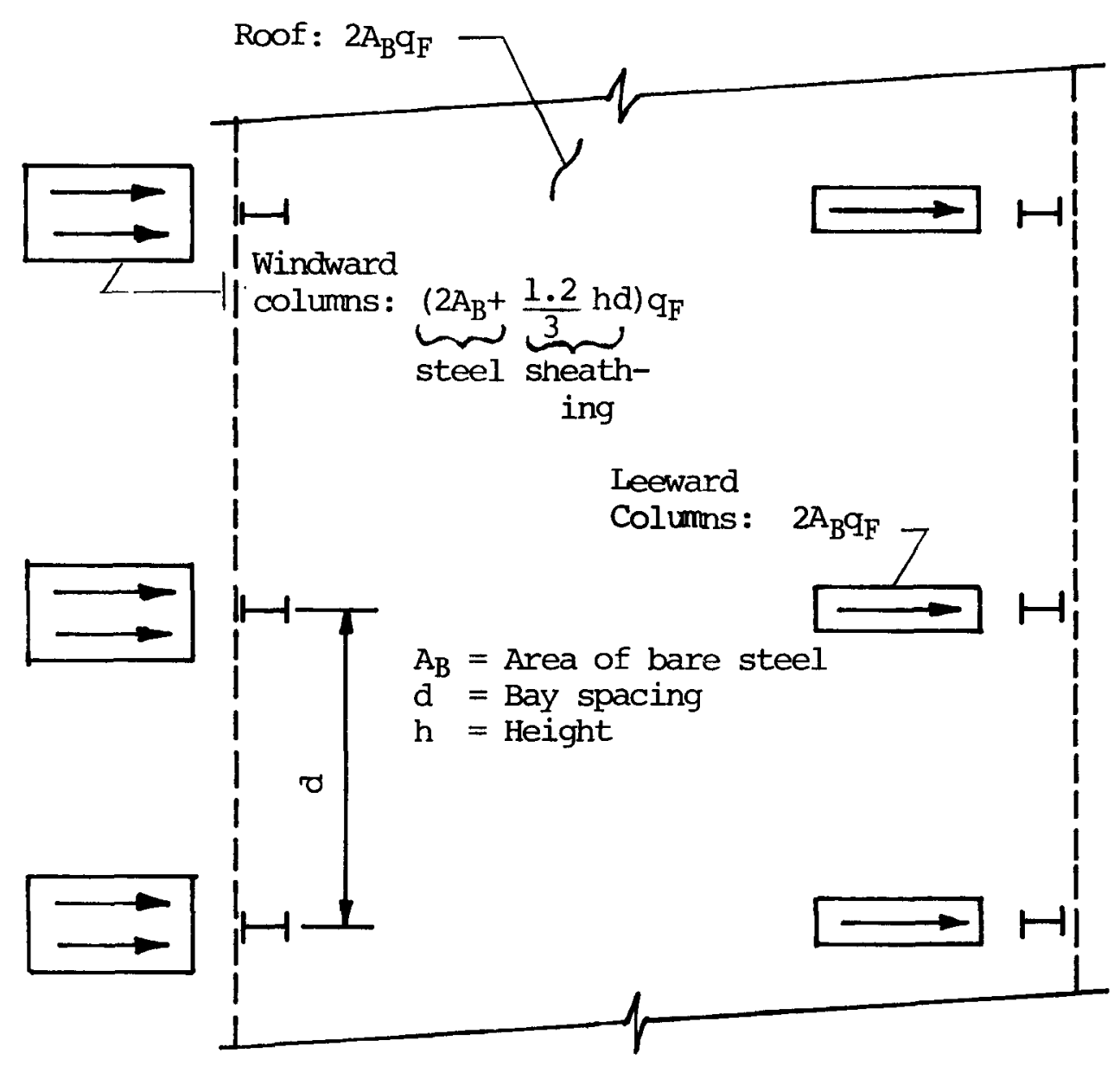

Drag coefficients:

Exposed Steel $C_{D}=2.0$

Remaining Sheathing $\mathrm{C}_{\mathrm{D}}=1.2$

FIGURE 4-6 Tornado Velocity Pressure Loading on Steel Frame with Detached Sheathing 


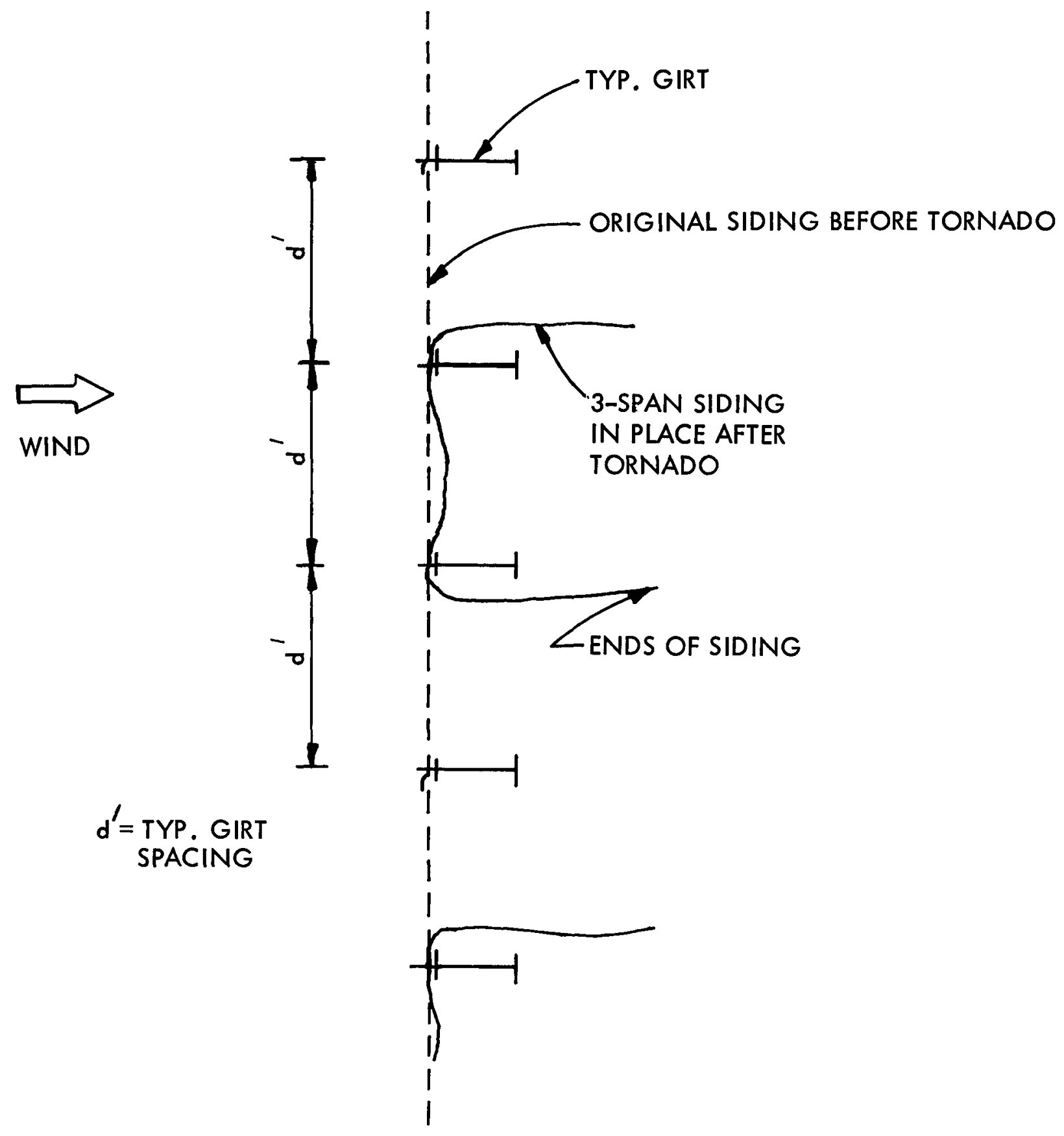

FIGURE 4-7 Typical Sheathing Failure Pattern (3-Span Sheathinq) |3 


\section{1}

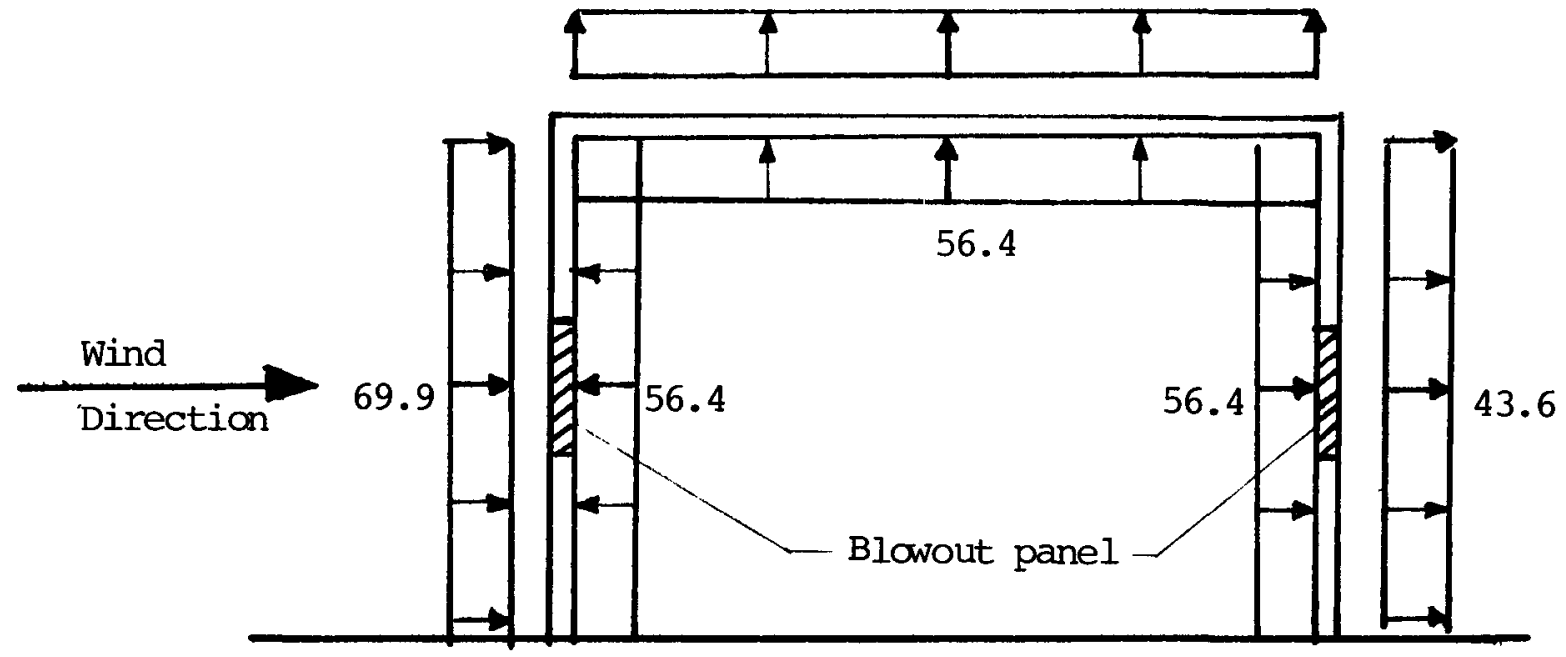

Pressures just prior to blowout panel release

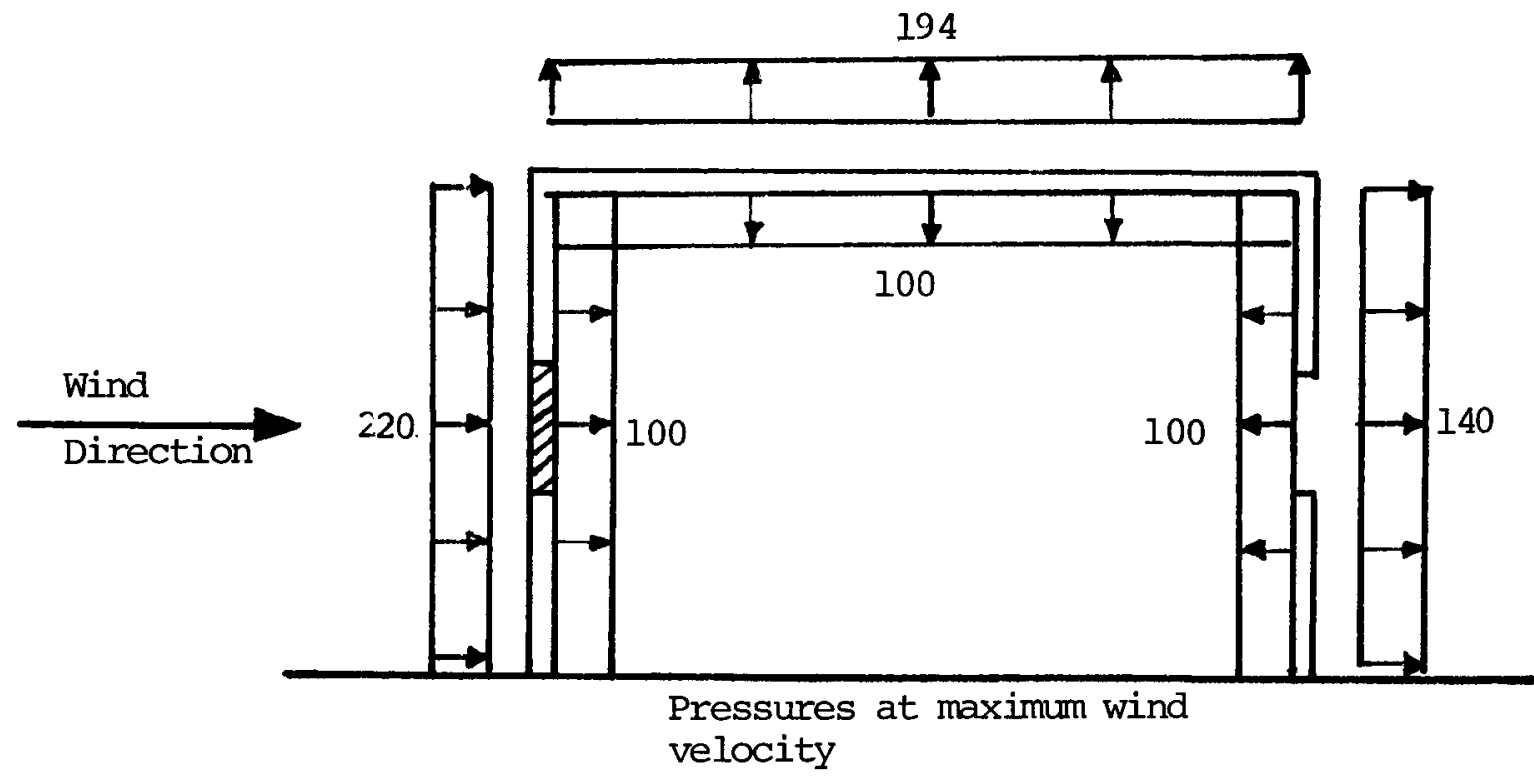

FIGURE 4-8 Pressures on Structure Before Blowout Panel Releases and at Maximum wind Velocity (psf) 


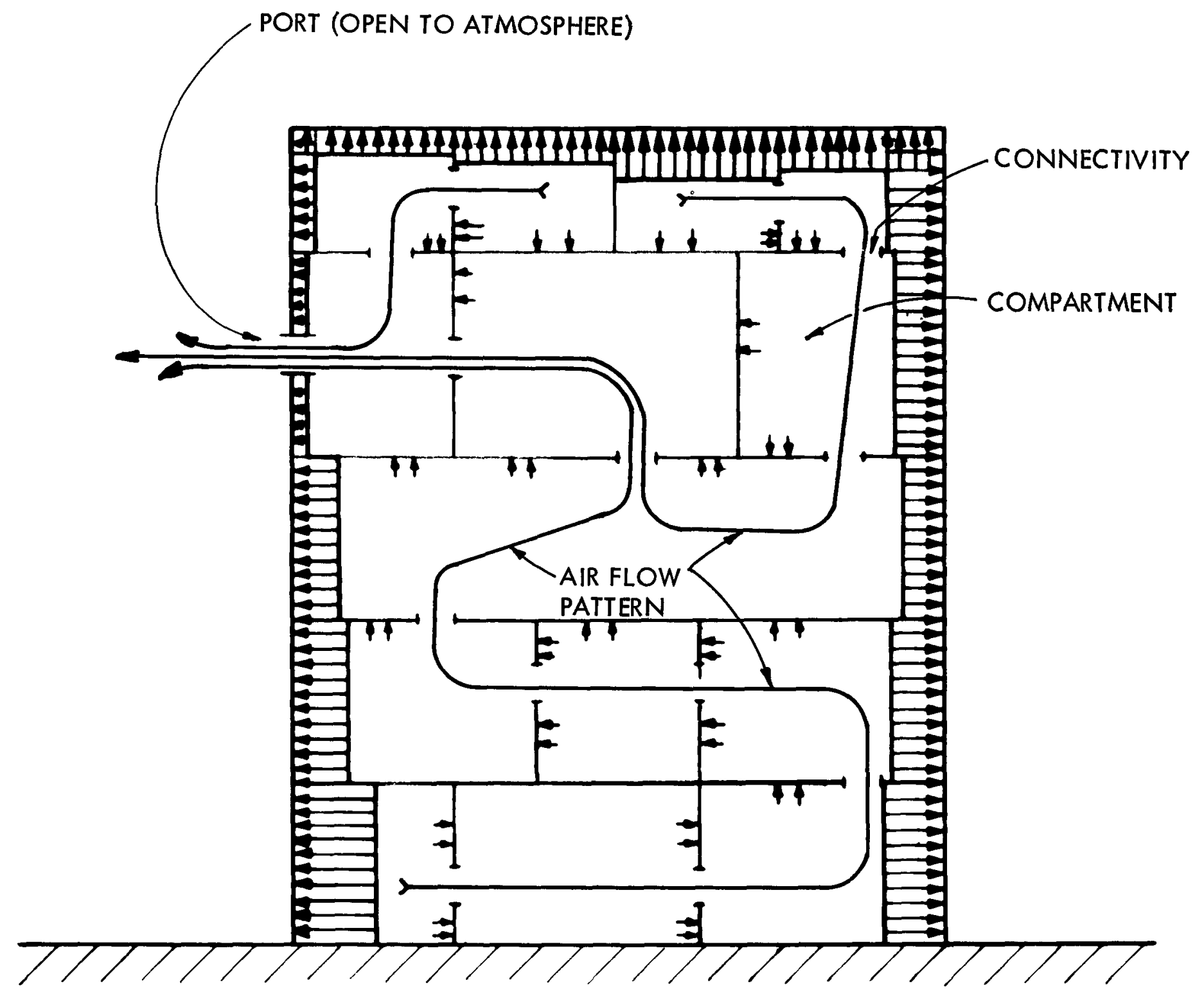

FIGURE 4-9 Illustration of Pressure Distribution and Flow Pattern During Building Depressurization 


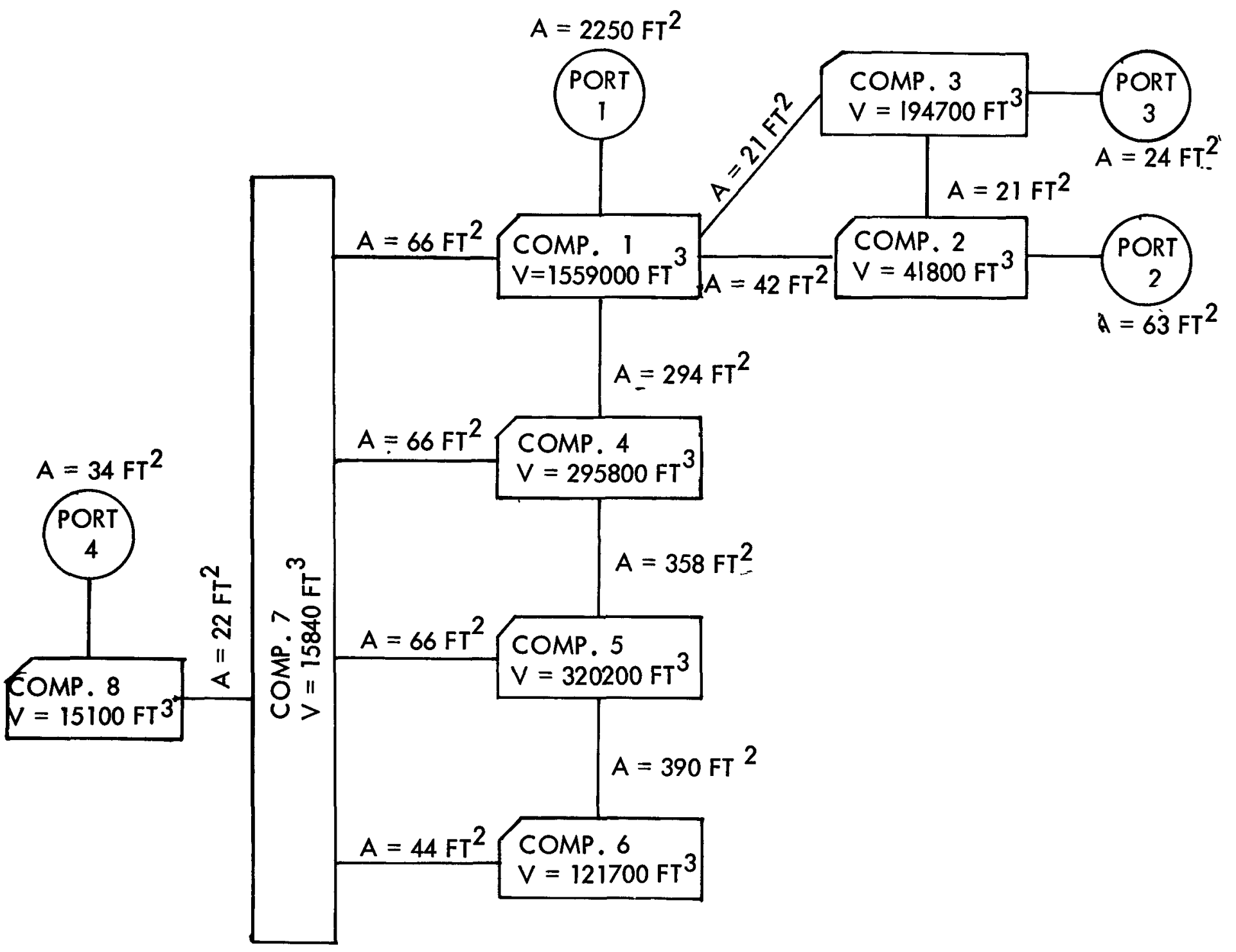

FIGURE 4-10 Illustration of a Structure Depressurization Model |3 


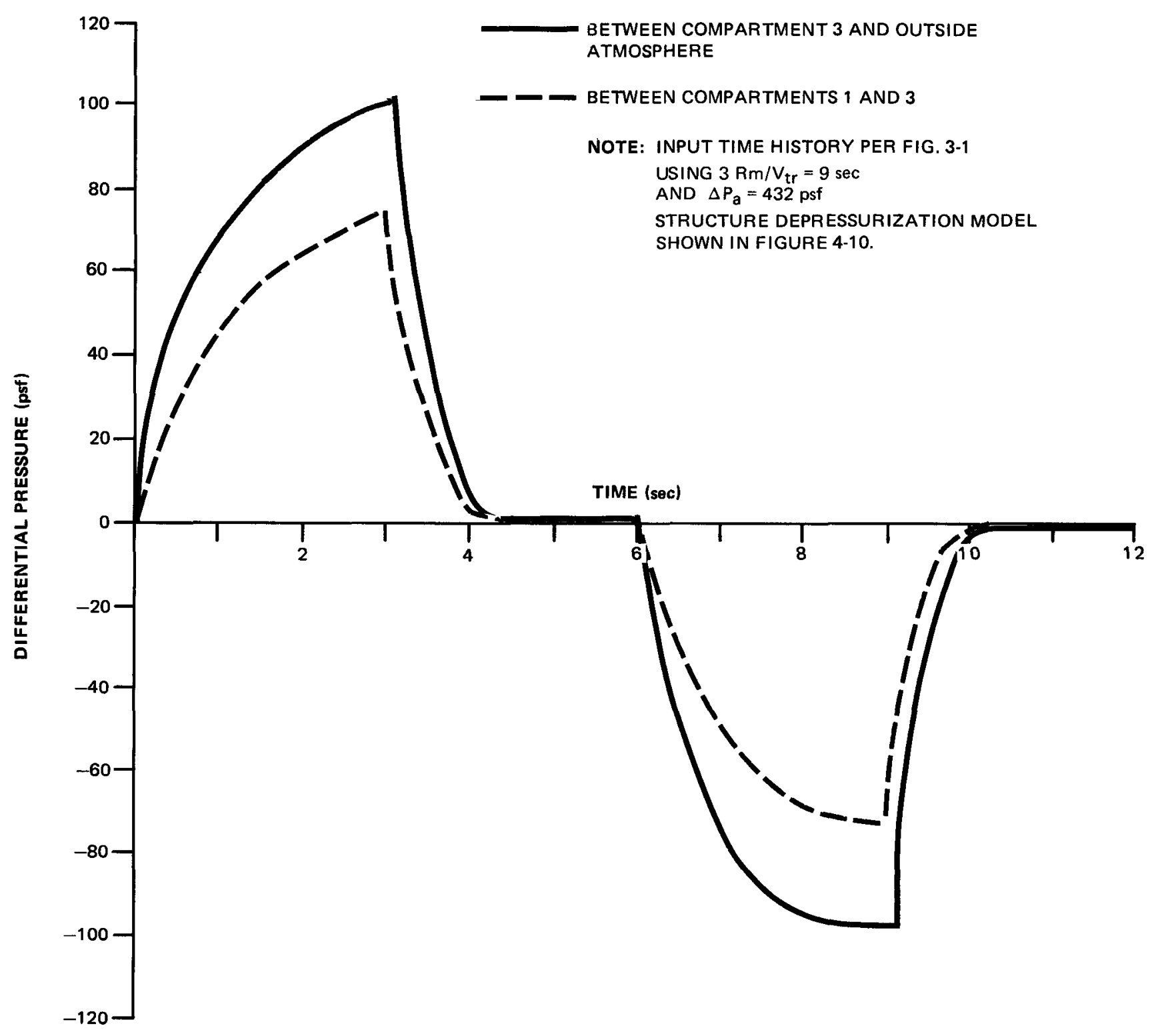

NOTE: THIS EXAMPLE IS FOR,ILLUSTRATION PURPOSES ONLY.

ATMOSPHERIC PRESSURE CHANGE

TIME HISTORY FOR DESIGN IS TO BE

OBTAINED FROM SAR.

FIGURE 4-11. DIFFERENTIAL PRESSURE-TIME HISTORY FOR COMPARTMENTS 1 AND 3 
Revision 3

\begin{tabular}{llllllllll}
$A$ & $P$ & $P$ & $E$ & $N$ & $D$ & $I$ & $X$ & & $A$ \\
\hline
\end{tabular}

CROSS REFERENCE LISTING

TO

AEC FORMAT 


\section{APPENDIX A}

CROSS REFERENCE LISTING TO AEC FORMAT

$\underline{\text { AEC Format }}$

$3 \cdot 3 \cdot 1 \cdot 1$

$3.3 \cdot 1.2$

$3 \cdot 3 \cdot 1 \cdot 3$

$3 \cdot 3 \cdot 1.4$

3.3 .2 .1

3.3 .2 .2

$3.3 .2 \cdot 3$
Description

$\underline{\mathrm{BC}-\mathrm{TOP}-3}$

Wind Loadings

Design Wind Velocity 2.0

Basis for Wind Velocity 2.0 Selection

Vertical Velocity

Distribution and Gust

Factor

Determination of

Applied Forces

\section{Tornado Loadings}

Applicable Design

Parameters

3.0

Determination of Forces on Structures

3.0

Ability of Category I Structures to Perform Despite Failure of Structures not Designed for Tornado Loads
2.0

2.0

2.0 
Revision 3

\begin{tabular}{lllllllll}
$A$ & $P$ & $P$ & $E$ & $N$ & $D$ & $I$ & $X$ & $B$ \\
\hline
\end{tabular}

NOTATION 


\section{APPENDIX B}

\section{NOTATION}

a $=$ Small dimension normal to wind.

A = Area upon which pressure is acting.

$\mathrm{A}_{1}=$ Area (on the side of compartment 1) of the wall between compartments 1 and 2 .

$\mathrm{A}_{2}=$ Area connecting compartments 1 and 2 .

$\mathrm{A}_{\mathrm{B}}=$ Projected area of bare steel.

$\mathrm{A}_{\mathrm{O}} \quad=$ Area of openings

$\mathrm{C}_{\mathrm{c}} \quad=$ compressibility coefficient.

$\mathrm{C}_{\mathrm{d}}=$ Discharge coefficient.

$\mathrm{C}_{\mathrm{v}} \quad=$ Velocity coefficient

C = Summation of pressure coefficients for obtaining velocity pressure loading on the structure or structural element.

$C_{D}=$ Drag coefficient

$\mathrm{C}_{\mathrm{f}} \quad=$ Net pressure coefficient.

$\mathrm{C}_{\mathrm{L}} \quad=$ Lift coefficient

$\mathrm{C}_{\mathrm{p}} \quad=$ Effective external pressure coefficient

$\mathrm{C}_{\mathrm{pi}}=$ Internal pressure coefficient

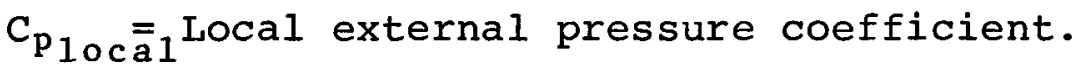

$\mathrm{C}_{\mathrm{q}} \quad=$ Velocity pressure factor.

$\mathrm{C}_{\mathrm{s}}=$ Ratio of average to maximum velocity pressure of tornado wind on structure or resisting element.

$\mathrm{F} \quad=$ Total force on strip of unit height.

g = Gravitational acceleration. 
G = Weight flow rate of air through an orifice.

$\mathrm{G}_{\mathrm{F}} \quad=$ Gust factor for calculating overall structural response - extreme wind.

$\mathrm{G}_{\mathrm{P}} \quad=$ Gust factor for parts and portions - extreme wind.

h = Height dimension.

k = specific heat of air at constant pressure divided by the specific heat of air at constant volume.

$\mathrm{K}=$ Ratio of vector sum of all velocity components to tangential velocity - tornado winds.

$\mathrm{K}_{1}=$ Ratio of loaded plan length of structure or structural element perpendicular to the direction of tornado wind to radius of maximum winds.

$k_{2}=$ Ratio of radius $r_{1}$ to radius of maximum wind, $R_{m}$.

$\mathrm{K}_{\mathrm{Z}} \quad=$ Height factor describing variations of extreme wind velocity with height.

$\ell=$ Long dimension normal to wind.

$\mathrm{L} \quad=$ Length of structure or structural element over which tornado velocity pressure is distributed.

$\mathrm{n}$ = Ratio of open area to solid area of wall having majority of openings.

$\mathrm{N} \quad=$ Number identifying compartment or opening.

$\mathrm{P}_{1}=$ Pressure in compartment 1 .

$\mathrm{P}_{2}=$ Pressure in compartment $2\left(\mathrm{P}_{2}<\mathrm{P}_{1}\right)$

$\mathrm{P}_{\mathrm{N}} \quad=$ Pressure in compartment $\mathrm{N}$.

$\mathrm{P}_{\mathbf{a}} \quad=$ Atmospheric pressure change.

$\Delta \mathrm{P}_{\mathrm{a}}=$ Maximum pressure change.

$\mathrm{P}_{\mathrm{ar}}=$ Atmospheric pressure change as a function of radius.

$\mathrm{P}_{\text {at }}=$ Atmospheric pressure change as a function of time. 


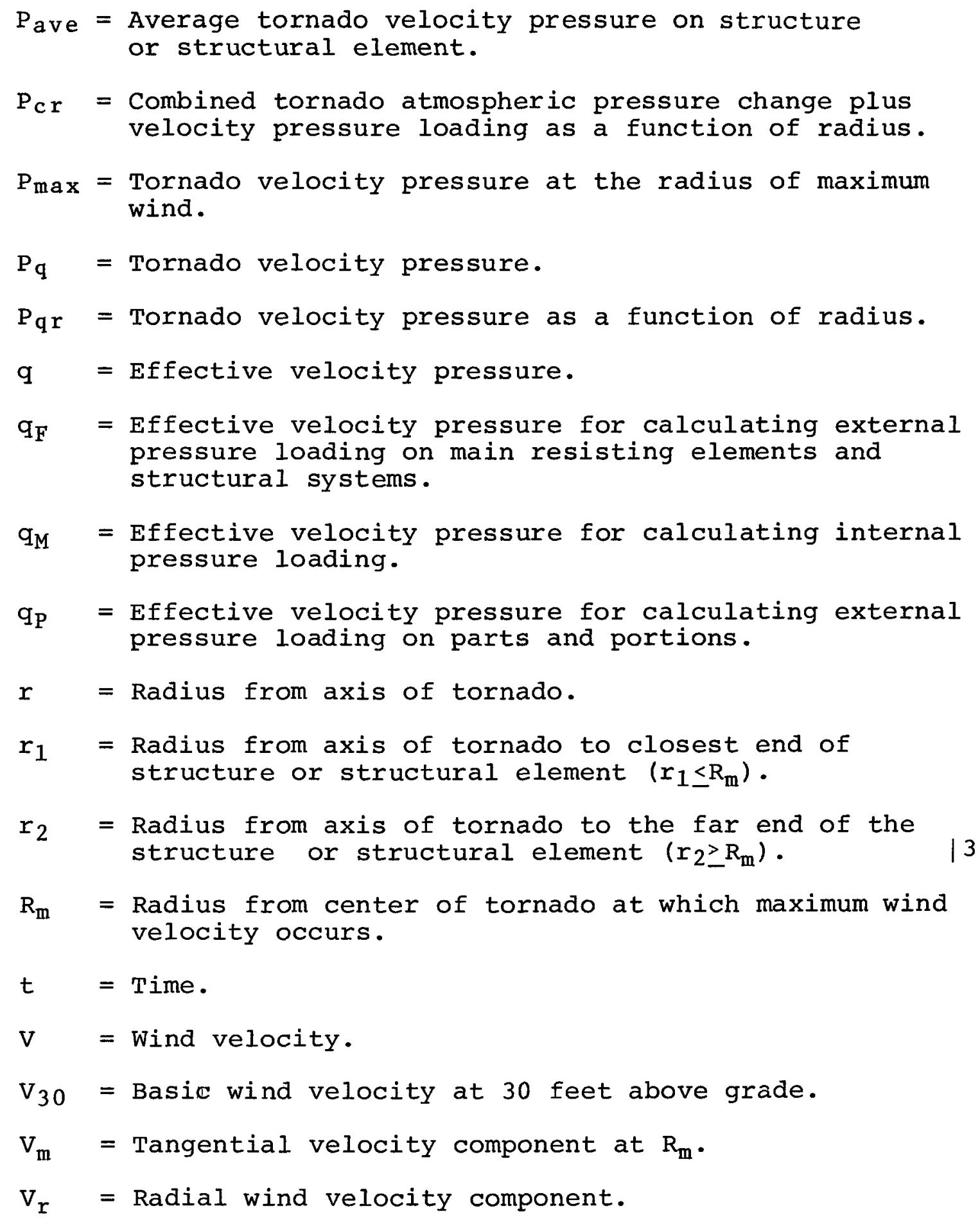


$\mathrm{V}_{\mathrm{t}} \quad=$ Tangential wind velocity component.

$v_{t r}=$ Translational velocity of tornado.

$\mathrm{w} \quad=$ Least width of building.

$\mathrm{W} \quad=$ Extreme wind loading.

$\mathrm{W}_{\mathrm{N}}=$ Weight of air in compartment $\mathrm{N}$.

$\mathrm{W}_{\mathrm{t}}$ = Tornado loading.

$\mathrm{W}_{\mathrm{tq}}=$ Tornado velocity pressure effects

$W_{t p}=$ Tornado atmospheric pressure change effects.

$\mathrm{W}_{\mathrm{tm}}=$ Missile impact effects.

$\mathrm{Z} \quad=$ Height in feet above grade.

$\gamma_{1}=$ Weight density of air in compartment 1 .

$\gamma_{N}=$ Weight density of air in compartment $N$.

$\rho \quad=$ Mass density of air.

$\theta \quad=$ Slope of roof in degrees from horizontal. 
Revision 3

$\begin{array}{lllllllll}A & P & P & E & N & D & I & X & C\end{array}$

SUPPORTING DERIVATIONS

FOR

TORNADO DESIGN CRITERIA 
The maximum combined effect of velocity pressure $\left(W_{t q}\right)$ and atmospheric pressure change $\left(W_{t} p\right)$ is determined from a combined set of equations for each effect expressed in terms of a common radial distance from the center of the tornado. Missile effects $\left(W_{t m}\right)$ are combined with $W_{t q}$ and $W_{t p}$ considering the missile trajectory and the zone within the wind field in which maximum missile velocities are attained.

1.1 Velocity Pressure Loading

Velocity pressure loading $\left(W_{t q}\right)$ on any structural element can be expressed in terms of velocity pressure, $q$, and combined pressure coefficient, $C$.

$$
\begin{aligned}
\mathrm{W}_{\mathrm{tq}}= & \Sigma \mathrm{Cq} \Delta \mathrm{A} \\
\mathrm{C}= & \text { summation of pressure coefficients } \\
& \text { for obtaining the velocity pressure } \\
& \text { loading on the structure or a parti- } \\
& \text { cular element. } \\
\mathrm{q}= & \text { velocity pressure. } \\
\Delta \mathrm{A}= & \text { area of portion of structure or element. } \\
\mathrm{q}= & \frac{1}{2} \rho \mathrm{V}^{2} \\
\rho= & \text { mass density of air. } \\
\mathrm{V}= & \text { wind velocity. }
\end{aligned}
$$

The wind velocity, $v$, can be expressed in terms of $r$ by considering $\mathrm{V}$ to be linearly proportional to the tangential velocity component, $\mathrm{V}_{t}$, and assuming that $v_{t}$ varies directly with radius, $r$, from the center of the tornado to the radius of maximum velocity, $\mathbf{R}_{\mathbf{m}}$, and inversely with $r$ at radii greater than $R_{m}$ (combined Rankine Vortex).

$$
\begin{array}{lll}
v_{t}=\frac{r}{R_{m}} v_{m} & 0<r \leq R_{m} & \text { (Eq. } C l-3 a) \\
v_{t}=\frac{R_{m}}{r} v_{m} & R_{m} \leq r<\infty & \text { (Eq. } C l-3 b) \\
v_{m}=\text { maximum tangential wind velocity. }
\end{array}
$$




$$
\begin{aligned}
& \mathrm{V}=\mathrm{KV} \mathrm{t}_{\mathrm{t}} \\
& \mathrm{K}=\text { proportionaity constant. }
\end{aligned}
$$

(Eq. $\mathrm{Cl}-4)$

Combining Equations $\mathrm{Cl}-1$ through $\mathrm{Cl}-4$, the net velocity pressure as a function of radius, $\mathrm{P}_{\mathrm{qr}}$, is:

$$
\begin{array}{lll}
\mathrm{P}_{\mathrm{qr}}=\frac{\rho \mathrm{K}^{2} \mathrm{C}}{2}\left[\frac{\mathrm{rV}}{\mathrm{R}_{\mathrm{m}}}\right]^{2} & 0 \leq \mathrm{r} \leq \mathrm{R}_{\mathrm{m}} & (\mathrm{Eq} \cdot \mathrm{Cl}-5 \mathrm{a}) \\
\mathrm{P}_{\mathrm{qr}}=\frac{\rho \mathrm{K}^{2} \mathrm{C}}{2}\left[\frac{\mathrm{R}_{\mathrm{m}} \mathrm{V}_{\mathrm{m}}}{\mathrm{r}}\right]^{2} & \mathrm{R}_{\mathrm{m}} \leq \mathrm{r}<\infty & (\mathrm{Eq} \cdot \mathrm{Cl}-5 \mathrm{~b})
\end{array}
$$

The maximum velocity pressure, $P_{q}$, occurs at $r=R_{m}$. A dimensionless plot of $P_{q r} / P_{q}$ vs. $r / R_{m}$ is shown in Figure 3-2.

\subsection{Atmospheric Pressure Change}

The atmospheric pressure gradient at radius $r$ is defined by the cyclostrophic wind equation:

$$
\frac{d P_{a r}}{d r}=\frac{\rho V_{t}^{2}}{r}
$$

With $V_{t}$ defined by Equations $\mathrm{Cl}-3 \mathrm{a}$ and $\mathrm{Cl}-3 \mathrm{~b}$, integration of Equation Cl-6 from infinity to $r$ defines the pressure drop at radius $r$.

$$
\begin{array}{lll}
P_{\text {ar }}=\frac{\rho V_{m}^{2}}{2}\left(2-\frac{r^{2}}{R_{m}^{2}}\right) & 0 \leq r \leq R_{m} & (E q \cdot C l-7 a) \quad \mid 3 \\
P_{a r}=\frac{\rho V_{m}^{2}}{2}\left(\frac{R_{m}^{2}}{r^{2}}\right) & R_{m} \leq r<\infty & (\mathrm{Eq} \cdot C l-7 b)
\end{array}
$$

A dimensionless plot of $P_{a r} / P_{a}$ vs. $r / R_{m}$ is shown in Figure $\mathrm{Cl}-1$ where $\mathrm{P}_{\mathrm{a}}$ is the maximum pressure drop (at $r=0$ ).

Building depressurization and repressurization calculations require determination of pressure change with respect to time. This is accomplished by substituting $r=V_{t r} t$ into Equations $c l-7 a$ and $C l-7 b$. 


$$
\begin{aligned}
& P_{a t}=\frac{\rho V_{m}^{2}}{2}\left(2-\frac{V_{t r}^{2} t^{2}}{R_{m}^{2}}\right) \quad 0 \leq r<R_{m} \quad(E q \cdot C l-7 c) \mid 3 \\
& P_{a t}=\frac{\rho V_{m}^{2}}{2}\left|\frac{R_{m}^{2}}{V_{t r}^{2} t^{2}}\right| \quad R_{m} \leq r<\infty \quad(E q \cdot C l-7 d) \\
& V_{t r}=\text { translational velocity. } \\
& t \quad=\text { time (reference to center of tornado). }
\end{aligned}
$$

An illustration of pressure drop variation with time is obtained by adding a time axis to Figure Cl-1. In lieu of Equations $\mathrm{Cl}-7 \mathrm{c}$ and $\mathrm{cl-7d}$, a more conservative idealized linear pressure-time curve can be used, assuming full pressure drop occurs in $R_{m} / V_{t r}$ seconds (see example superimposed plot - Fig. Cl-I).

1.3 Wind Load Plus Pressure Drop

The combined effect of velocity pressure and atmospheric pressure change is the summation of $\mathrm{P}_{\mathrm{qr}}$ and $\mathrm{P}_{\text {ar }}$.

$$
\mathrm{P}_{\mathrm{c} r \mathrm{r}}=\mathrm{P}_{\mathrm{qr}}+\mathrm{P}_{\mathrm{ar}}
$$

(Eq. $\mathrm{Cl}-8)$

Substituting the values for $\mathrm{P}_{\mathrm{qr}}$ and $\mathrm{P}_{\mathrm{ar}}$ (as determined by Equations $\mathrm{Cl}-5 \mathrm{a}, \mathrm{Cl}-5 \mathrm{~b}$ and $\mathrm{Cl}-7 \mathrm{a}$ and $\mathrm{Cl}-7 \mathrm{~b}$ ) into Equation $\mathrm{Cl-8}$ yields the following formulae for $\mathrm{P}_{\mathrm{cr}}$ in terms of $r$.

$$
P_{c r}=\frac{\rho V_{m}^{2}}{2}\left[2+\frac{r^{2}}{R_{m}^{2}}\left(K^{2} C-1\right)\right] \quad 0 \leq r \leq R_{m}
$$

(Eq. Cl-9a)

$$
P_{c r}=\frac{\rho V_{m}^{2}}{2} \frac{R_{m}^{2}}{r^{2}}\left(1+K^{2} c\right)
$$

$\mathrm{R}_{\mathrm{m}} \leq \mathrm{r}<\infty$

(Eq. Cl-9b)

Equation $\mathrm{Cl}-9 \mathrm{a}$ shows that $\mathrm{P}_{\mathrm{cr}}$ will be a maximum at $r=0$ or at $r=R_{m}$ depending on the value of $K^{2} C$. For $\mathrm{K}^{2} \mathrm{C}<1, \mathrm{P}_{\mathrm{cr}}$ is a maximum at $\mathrm{r}=0$ and is equal to the full value of maximum atmospheric pressure change (see Equation $\mathrm{Cl}-7 \mathrm{a}$ ). For $\mathrm{K}^{2} \mathrm{C}>1, \mathrm{P}_{\mathrm{cr}}$ is a maximum at $r=R_{m}$ and is equal to maximum velocity pressure effects plus one-half of maximum atmospheric pressure change. 
Equation $\mathrm{Cl}-9 \mathrm{~b}$ shows that $\mathrm{P}_{\mathrm{cr}}$ will be a maximum only at $r=R_{m}$ (regardless of the value of $K^{2} C$ ) and again will be equal to maximum velocity pressure effects plus one-half of maximum atmospheric pressure change.

For structures with openings, loading due to atmospheric pressure change may approach zero (as for completely open structures). Therefore, the load case of velocity pressures acting alone must be considered.

These considerations result in the following design load equations:

Velocity pressure acting alone:

$$
\mathrm{w}_{\mathrm{t}}=\mathrm{w}_{\mathrm{tq}}
$$

$(\mathrm{Eq} \cdot \mathrm{Cl}-10)$

Atmospheric pressure change acting alone:

$$
\mathrm{w}_{\mathrm{t}}=\mathrm{w}_{\mathrm{tp}}
$$

(Eq. $\mathrm{Cl}-11)$

Velocity pressure concurrent with atmospheric pressure change:

$$
\mathrm{w}_{\mathrm{t}}=\mathrm{w}_{\mathrm{tq}}+0.5 \mathrm{w}_{\mathrm{tp}}
$$

These equations are identical to Equations 3-1, 3-2 and 3-4 in Section 3.

\subsection{Missile Load Combinations}

Missiles within a tornado wind field tend to be ejected from the tornado. The maximum missile velocity is obtained when the missile is near but outside of the radius of maximum wind $\left(R_{m}\right)$. For design purposes, missiles are therefore assumed to strike a structure at or near the radius of maximum wind at which time the structure is subjected to full velocity pressure effects plus one-half atmospheric pressure change. Since the missile may also be ejected from the tornado before striking the structure, missile effects are considered acting independently or in combination with velocity pressure and atmospheric pressure change. This results in the following design load equations: 
Missile acting alone:

$$
\mathrm{w}_{\mathrm{t}}=\mathrm{w}_{\mathrm{tm}}
$$

(Eq. $\mathrm{Cl}-13)$

Missile impact concurrent with wind loads:

$$
w_{t}=w_{t q}+w_{t m}
$$

Missile impact concurrent with wind load and atmospheric pressure change:

$$
\mathrm{w}_{\mathrm{t}}=\mathrm{w}_{\mathrm{tq}}+0.5 \mathrm{w}_{\mathrm{tp}}+\mathrm{w}_{\mathrm{tm}}
$$

These equations are identical to Equations $3-3,3-5$ and $3-6$ in section 3 .

2.0 STRUCTURE SIZE EFFECT ON VELOCITY PRESSURE LOADING

The tornado wind velocity varies with distance from the center of the tornado $(r)$ but is assumed (conservatively) not to vary with height. The total load on a structure (or structural element) is therefore a direct function of its plan dimension, L, perpendicular to the direction of wind.

The total load will be a maximum when the radius of maximum wind speed falls within the length, L. Referring to Figure 3-3:

$$
\begin{aligned}
& r_{1}<R_{m}<r_{2} \\
& L=r_{2}-r_{1}
\end{aligned}
$$

An integration of the velocity pressure profile (defined by Equations $\mathrm{Cl}-5 \mathrm{a}$ and $\mathrm{Cl}-5 \mathrm{~b}$ ) on a horizontal strip between limits of $r_{1}$ and $r_{2}$ results in the. following expression for total force on a unit width strip of length, $L$.

$$
\begin{aligned}
F= & \frac{\rho \mathrm{CK}^{2} v_{\mathrm{m}}^{2}}{2}\left[\frac{4}{3} \mathrm{R}_{\mathrm{m}}-\frac{\mathrm{r}_{1}^{3}}{3 \mathrm{R}_{\mathrm{m}}^{2}}-\frac{\mathrm{R}_{\mathrm{m}}^{2}}{\mathrm{r}_{2}}\right] \\
& \begin{array}{c}
0 \mathrm{r}_{1} \leq \mathrm{R}_{\mathrm{m}} \\
\mathrm{R}_{\mathrm{m}} \leq \mathrm{r}_{2}<\infty
\end{array}
\end{aligned}
$$

$(\mathrm{Eq} \cdot \mathrm{C} 2-2)$ 
From examination of Equation $\mathrm{C} 2-2$, it is found that $\mathrm{F}$ is a maximum when the structure is positioned such that $r_{1}=R^{2} / r_{2}$.

Making the following substitutions into Equation C2-2;

$$
\begin{aligned}
& K_{2}=\frac{-K_{1}+\sqrt{K_{1}^{2}+4}}{2} \\
& L=K_{1} R_{m} \\
& r_{1}=K_{2} R_{m} \\
& P_{\text {ave }}=\frac{F}{I} \\
& P_{\text {max }}=\frac{\rho C K^{2} v_{m}^{2}}{2}
\end{aligned}
$$

The ratio of average pressure to maximum pressure is:

$$
\frac{\mathrm{P}_{\text {ave }}}{\mathrm{P}_{\max }}=\frac{4}{3 \mathrm{~K}_{1}}-\frac{\mathrm{K}_{2}^{3}}{3 \mathrm{~K}_{1}}-\frac{1}{\left(\mathrm{~K}_{1}+\mathrm{K}_{2}\right) \mathrm{K}_{1}} \quad \text { (Eq. C2-4) }
$$

A plot of Equation C2-4 ( $\left.\mathrm{P}_{\mathrm{ave}} / \mathrm{P}_{\mathrm{max}} \mathrm{vs} . \mathrm{K}_{1}\right)$ is shown in Figure 3-3.

Knowing the maximum velocity pressure $\left(\mathrm{P}_{\max }\right)$ and the ratio of structure length to radius of maximum wind velocity $\left(L / R_{m}=K_{1}\right)$, the average pressure ( $P_{\text {ave }}$ ) can be determined directly from Figure 3-3. The value of $R_{m}$ is specified in the plant SAR. 
Time* (sec)

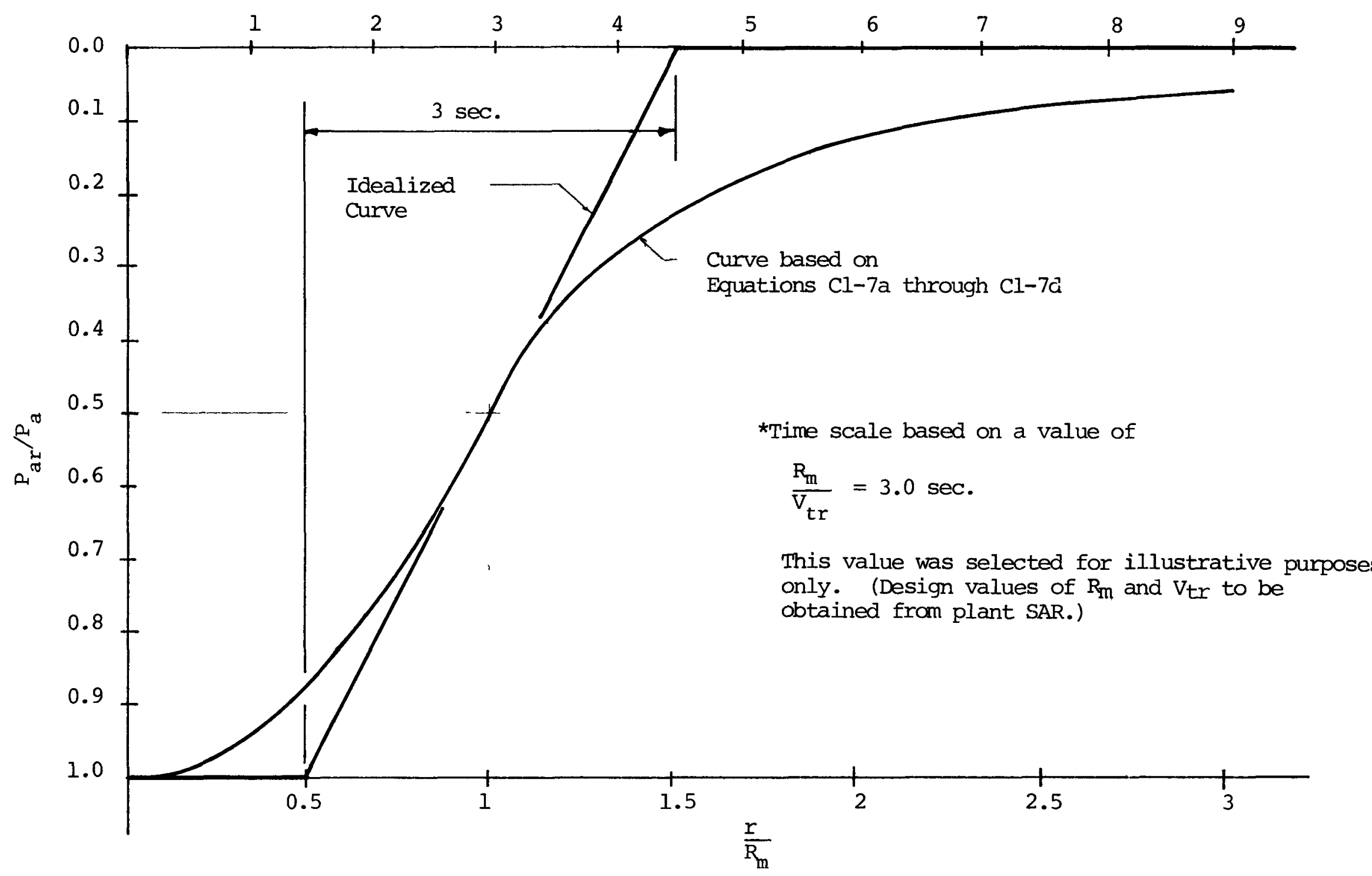

FIGURE Cl-1 Atmospheric Pressure Change Variations With Radius And Time 
\begin{tabular}{lllllllll}
$A$ & $P$ & $P$ & $E$ & $N$ & $D$ & $I$ & $X$ & $D$ \\
\hline
\end{tabular}

COMPUTER PROGRAM

FOR

BUILDING DEPRESSURIZATION

BECHTEL CORPORATION PROGRAM CE 899 
APPENDIX D

COMPUTER PROGRAM

FOR

BUILDING DEPRESSURIZATION

BECHTEL CORPORATION PROGRAM CE 899

\subsection{PROGRAM CAPABILITY}

Bechtel Corporation program $C E 899$ is used to calculate differential pressures between compartments within buildings and across interior and exterior surfaces of a building subjected to tornado-induced time-dependent atmospheric pressure change.

\subsection{Theory and Equations}

Laws for quasi-steady, one-dimensional motion of an ideal compressible gas are used to calculate the flow of air in the structure and the differential pressure history with the three-dimensional effects taken into account by a factor of safety.

The weight flow rate of air and the relationship between pressure and air weight-density are based on an adiabatic process.

\subsubsection{Weight Flow Rate}

The weight flow rate, $G$, of air passing through an orifice is defined as follows (from Ref. 20):

$$
\begin{array}{ll}
G=C_{v} C_{c} A_{2}\left[2 g \gamma_{1}\left(p_{1}-p_{2}\right)\right]^{\frac{1}{2}} & (E q \cdot D-1) \\
C_{v}=C_{d}\left[1-\left(A_{2} / A_{1}\right)^{2}\right]^{-\frac{1}{2}} & \text { (Eq. D-2) }
\end{array}
$$

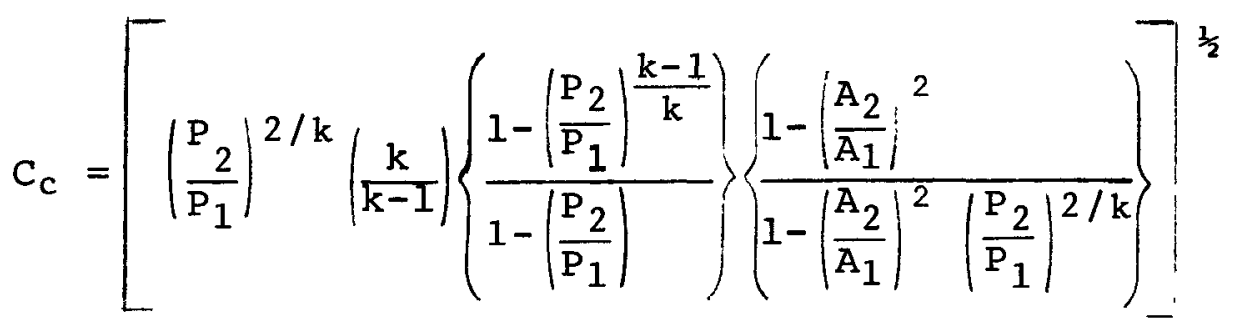

(Eq. D-3)

$$
\mathrm{D}-1
$$




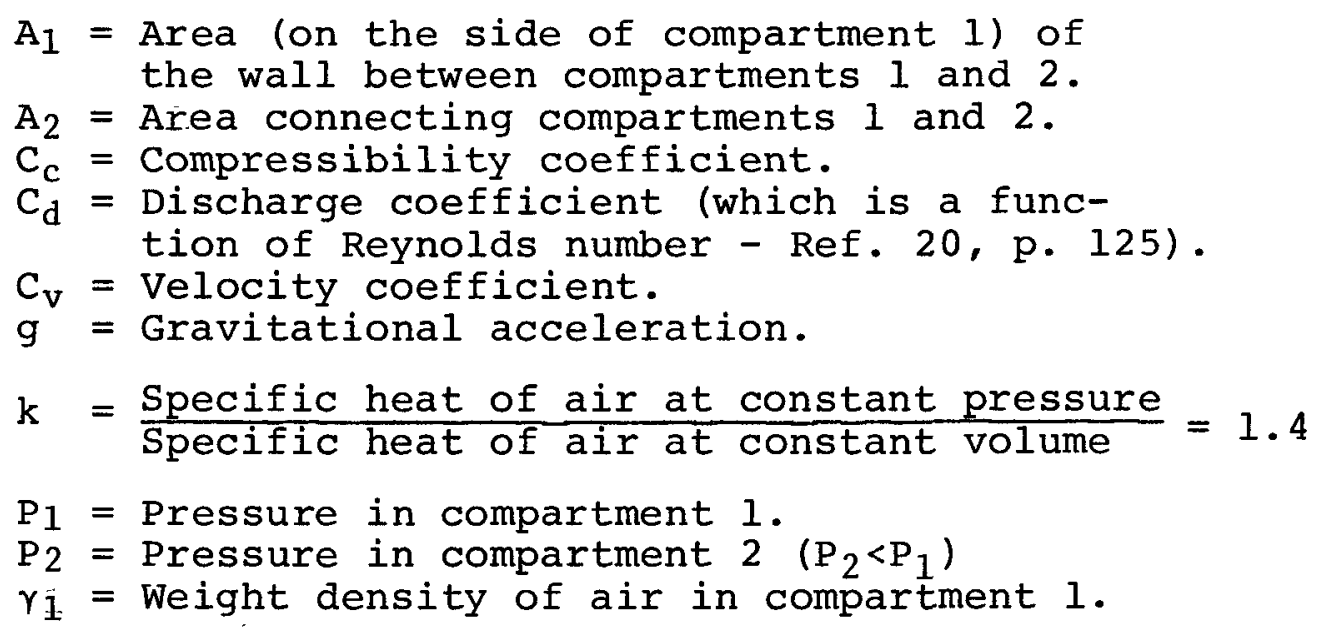

Equation D-1 is valid if the flow through the orifice is subcritical. The flow is subcritical when the conditions of Equation D-4 are satisfied (Ref. 21).

$$
1>\frac{\mathrm{P}_{2}}{\mathrm{P}_{1}}>0.528 \quad \text { (Eq. D-4) }
$$

\subsubsection{Pressure Weight-Density Relationship}

The following relationship between pressure and weightdensity is assumed to be constant:

$$
\begin{aligned}
& P_{N} \gamma_{N}^{-k}=\text { a constant } \\
& P_{N}=\text { Pressure in compartment } N \text {. } \\
& \gamma_{N}=\text { Weight-density of air in compartment } N .
\end{aligned}
$$

Within each time increment, $\Delta t$, the flow is assumed to be steady and subcritical. The weight of air in compartment $N, W_{N}$, at time $t_{i+1}$ is therefore:

$$
w_{N}\left(t_{i+1}\right)=w_{N}\left(t_{i}\right)+\left[G_{N}(i n)\left(t_{i}\right)-G_{N}(\text { out })\left(t_{i}\right)\right] \Delta t
$$

(Eq. D-6)

The weight flow rate, $\mathrm{G}_{\mathrm{N}}$, is defined by Equation $\mathrm{D}-1$. Since the volume of each compartment remains constant, the ratio of weight densities is equal to the ratio of weights:

$$
\gamma_{N}\left(t_{i+1}\right) / \gamma_{N}\left(t_{i}\right)=w_{N}\left(t_{i+1}\right) / w_{N}\left(t_{i}\right) \quad(E q \cdot D-7)
$$


The pressure in compartment $\mathrm{N}$ at $t_{i m e} t_{i+1}$ is therefore, (from Equation D-5):

$$
P_{N}\left(t_{i+1}\right)=\left[w_{N}\left(t_{i+1}\right) / w_{N}\left(t_{i}\right)\right]^{k} P_{N}\left(t_{i}\right) \quad(E q \cdot D-8)
$$

1.1.3 Three-Dimensional Effects

It is recognized that the one-dimensional analysis yields conservative differential pressures on all interior walls of a building. A 1.20 factor of safety shall be applied to the computed differential pressures on exterior walls to account for possible non-conservatism due to the three-dimensional effects.

\subsection{Computer Operations}

Equations $D-1, D-6$ and $D-8$ are used in the program along with the input atmospheric pressure change timehistory, the description of blowout panels (if present), the geometry of the structure, and the order of interconnecting the compartments to evaluate the differential air pressures on internal and external walls.

During each time increment (usually 0.01 second or less), the air flowing from connecting compartments into compartment $\mathrm{N}$ is computed, taking each connecting compartment separately. The pressure is held constant in compartment $N$ and the flow from all connecting compartments is computed. Then, half of the computed inflow air from each connecting compartment is added to the air in compartment $N$. The flow of air into compartment $N$ is computed again for the same increment (at time $t_{i}$ ), with an adjusted pressure and the adjusted amount of air in compartment $N$ is calculated before proceeding to the next time increment (at time $t_{i+1}$ ).

If a blowout panel exists in a compartment, the differential pressure is checked to see whether the design pressure has been exceeded. If it has been exceeded, the area of the blowout panel becomes a new outlet for the compartment to a connected compartment or to the outside atmosphere. 


\subsection{Input Data}

The input data required for the program are as follows:

1. Total transient time and time integration interval.

2. Table of weight density of air vs. pressure.

3. Table of atmospheric pressure vs. time.

4. Number of compartments, number of ports, number of intercompartment connections, initial pressure for all compartments and ports, velocity coefficient, $\mathrm{C}_{\mathrm{v}}$ and compressibility coefficient, $C_{c}$. If not specified, the values of $\mathrm{C}_{\mathrm{v}}=0.6$ and $\mathrm{C}_{\mathrm{c}}=0.98 \mathrm{will}$ be used in the program.

5. Compartment and connectivity list, including the compartment volume and whether it is connected to a port.

6. Port and port area table giving initial port area, blowout panel area and blowout pressure.

7. Intercompartment area table giving initial connecting area, blowout panel area and blowout pressure.

Most of the data required for the program can be established from the geometry of the structure and the interconnection of compartments. Values of $\mathrm{C}_{\mathrm{v}}$ and $\mathrm{C}_{\mathrm{c}}$ can be assigned using data for standard orifices such as those contained in References 22 and 23 as a guide.

\section{4 Example}

An example of a structure depressurization model defining compartment volumes, connectivity, ports and interior vents is described in Section 4-6 and Figure 4-10. A typical differential pressure-time history resulting from an atmospheric pressure-time function (Figure 3-1) applied to this model is shown in Figure 4-11. 
Revision 3

\begin{tabular}{lllllllll}
$A$ & $P$ & $P$ & $E$ & $N$ & $D$ & $I$ & $X$ & $E$ \\
\hline
\end{tabular}

REFERENCES 


\title{
APPENDIX E
}

\author{
REFERENCES
}

1. "American National Standard Building Code Requirements for Minimum Design Loads in Buildings and Other Structures", American iJational Standards Institute, A58.1-1972.

2. ASCE Committee Report, "Wind Forces on Structures", Transactions of the ASCE, Paper No. 3269, 1961.

3. Bechtel Power Corporation, "Design of Structures for Missile Impact", Topical Report BC-TOP-9, Rev. 1, July, 1973.

4. "Seismic Design Classification", Regulatory Guide 1.29, Directorate of Regulatory Standards, U. S. Atomic Energy Commission, Revision 1, August 1973.

5. Irish, K., and R. Cochrane, "Wind Vibration of Chimneys", ACI Journal, September, 1972.

6. Kessler, E., (of National Severe Storms Laboratory), letter to $\mathrm{H}$. Denton, on the Subject of windspeed and regional characteristics of tornadoes, April 25, 1973.

7. Bechtel Corporation, "Design Criteria for Nuclear Power Plants Against Tornadoes", Topical Report B-TOP-3, March 12,1970 .

8. Shanahan, J. A., "Engineering Report on the Lubbock Tornadoes of May 11, 1970", Bechtel Corporation, Power and Industrial Division, San Francisco, Calif., October, 1972 .

9. Flora, S. D., "Tornadoes of the United States", University of Oklahoma Press, Norman, Oklahoma, 1953.

10. Reynolds, G. W., "Venting and Other Building Practices as Practical Means of Reducing Damage from Tornado Low Pressures", Bulletin, American Meteorological Society, January, 1958 . 
11. Fujita, T. T., "Estimate of Maximum Windspeeds of Tornadoes in Southernmost Rockies", SMRP Research Paper No. 105, The University of Chicago, June, 1972.

12. Fujita, T. T., "Estimate of Maximum Windspeeds of Tornadoes in Three Northwestern States", SMRP Research Paper No. 92, The University of Chicago, 1970.

13. Fujita, T. T., "A Detailed Analysis of the Fargo Tornadoes", U. S. Department of Commerce, Weather Bureau, Research Paper No. 42, December, 1960.

14. Fujita, T. T., D. L. Bradbury, and P. G. Black, "Estimation of Tornado Wind Speeds from Characteristic Ground Marks", SMRP Research Paper No. 69, The University of Chicago, 1967.

15. Fujita, T. T., D. L. Bradbury, and C. F. Van Thullerar, "Palm Sunday Tornadoes of April 11, 1965", Monthly Weather Review, 98, No. 1, 1970, pp. 29-69.

16. Hoecker, W. H., "Wind Speed and Air Flow Patterns in the Dallas Tornado of April 2, 1957", Monthly Weather Review, May, 1960 , pp. 167-180.

17. Lewis, W., and P. T. Perkins, "Recorded Pressure Distribution in the Outer Portions of a Tornado Vortex", Monthly Weather Review, December, 1953.

18. McDonald, J. R., "Structural Response of a Twenty Story Building to the Lubbock Tornado", Texas Technical University, TTU-SSR-01, October, 1970.

19. Mehta, K. C., et al., "Response of Structural Systems to the Lubbock Storm", Texas Technical University, TTU-SSR03, October, 1971.

20. Binder, R. C., Fluid Mechanics, Second Edition, PrenticeHall, Inc., New York, New York, 1949.

21. Eshbach, O. W., Handbook of Engineering Fundamentals, Second Edition, John Wiley \& Sons, Inc., 1952.

22. "Flow of Fluids Through Valves, Fittings, and Pipe", Technical Paper No. 410 , Crane Co., 300 Park Avenue, New York, New York, 10022, 1969.

23. Perry, J. A., "Critical Flow Through Sharp-Edged Orifices", Trans., ASME, October, 1949, pp. 757-764. 